Revista lus et Praxis, Año 25, № 1, 2019, pp. 195 - 250

ISSN 0717 - 2877

Universidad de Talca - Facultad de Ciencias Jurídicas y Sociales

Tutela colectiva y principios procesales. Las necesarias limitaciones

del principio dispositivo en los procesos colectivos

Ana María Neira Pena

Trabajo recibido el 15 de mayo de 2017 y aprobado el 13 de octubre de 2018

\title{
Tutela colectiva y principios procesales. Las necesarias limitaciones del principio dispositivo en los procesos colectivos
}

\author{
ColleCtive JUdicial PROTECTION AND PROCEDURAL PRINCIPLES. NeCESSARY \\ RESTRICTIONS ON THE DISPOSITIVE PRINCIPLE IN CLASS ACTIONS
}

Ana María Neira Pena*

\begin{abstract}
RESUMEN
En este trabajo se analizan los principios que informan la tutela colectiva frente a la tutela civil tradicional. Para ello se confrontan dos regulaciones, la contenida en la Ley de enjuiciamiento civil española, carente de un auténtico sistema de acciones colectivas, y la contenida en el Código Modelo de procesos colectivos para Iberoamérica que, consciente de las especificidades de la tutela colectiva, configura un auténtico sistema de tutela judicial colectiva efectiva.
\end{abstract}

\section{ABSTRACT}

This paper analyzes the principles that inform the collective judicial protections compared to those of the traditional civil remedies. To this end, two regulations are confronted: that contained in the Spanish Civil Procedure Act, lacking a genuine system of collective actions, and that contained in the Model Code of Collective Procedures for Ibero-America, which is aware of the specificities of collective actions, and contains a real system of effective collective judicial protection.

\section{Palabras Clave}

Tutela colectiva, acciones de clase, principio dispositivo

KEY WORDS

Collective judicial protection, class actions, dispositive principle

\section{Introducción}

El presente trabajo tiene por objeto analizar cuáles son los principios que informan la tutela judicial colectiva frente a los propios de la tutela individual. Para ello se tratará de analizar cómo y porqué surgen las acciones colectivas y qué especificidades presentan o debieran presentar estos procesos frente a los tradicionales, atendiendo a las funcionalidades que sirven y a las finalidades que persiguen.

\footnotetext{
* Profesora Ayudante Doctora (Acreditada como Profesora Contratada Doctora). Área de Derecho Procesal (Departamento de Derecho Público), Universidade da Coruña, A Coruña (España).
} 
A diferencia de otros países, en los que se ha regulado un sistema completo de acciones colectivas, en España, el legislador se ha conformado con introducir una decena de preceptos a lo largo del articulado de la Ley $N^{\circ}$ 1/2000, de 7 de enero, de enjuiciamiento civil (en adelante LECiv), en los que se trata de dar respuesta a cuestiones concretas, tales como la legitimación, la determinación de los miembros del grupo, las formas de comunicación con tales sujetos para informarles de la existencia del proceso, los efectos de la cosa juzgada y las posibilidades de ejecución de las resoluciones que ponen fin al proceso colectivo.

Estas soluciones, parciales y fragmentarias, se insertan en el texto de una ley procesal, como es la LECiv, concebida únicamente para procesos individuales, desconociendo, por lo tanto que, tal y como señala la Exposición de Motivos del Código Modelo de procesos colectivos para Iberoamérica (en adelante Código Modelo) ${ }^{1}$, el proceso tradicional no sirve para una tutela eficaz de los derechos e intereses transindividuales.

Pues bien, lo que se pretende poner de manifiesto en este trabajo es que ciertos principios procesales clásicos y, más concretamente, alguno de los principios que informan la justicia civil, han de ser matizados en relación con la tutela colectiva. De ahí la conveniencia de que la LECiv establezca un verdadero sistema de acciones colectivas, sin que la regulación fragmentaria de algunas problemáticas concretas, de entre las muchas que plantean estas acciones, pueda insertarse sin más en un sistema procesal civil tradicional, absolutamente ajeno a las necesidades de tutela de los intereses colectivos.

Como señala Vázquez Sotelo "las categorías del proceso colectivo suponen una verdadera subversión en los conceptos e instituciones fundamentales del proceso civil de litigios individuales" ${ }^{\prime 2}$, alcanzando esta revolución, como se tratará de explicar, incluso, a los principios informadores del proceso civil más indiscutiblemente aceptados por la doctrina y más rigurosamente implantados en la legislación.

\section{Del derecho subjetivo a los derechos de grupo}

El tema de los poderes del juez civil es un asunto fuertemente ideologizado. Los defensores de la "publicización" del proceso civil, esto es, de la atribución de ciertos poderes al juez en la dirección material del proceso $y$, concretamente, en materia de prueba, critican a los defensores de la

1 El Código Modelo de Procesos Colectivos para Iberoamérica, realizado por el Instituto Iberoamericano de Derecho Procesal, fue aprobado en Caracas el 28 de octubre de 2004.

${ }^{2}$ VÁzQuez (2007), p. 902. 
privatización del proceso por defender un sistema "ultraliberal"3. Por su parte, estos últimos, también introducen en el debate fundamentos puramente ideológicos, tachando a los primeros de autoritarios. En este sentido, apunta Montero Aroca ${ }^{4}$ que la posición caracterizada por la atribución al juez del deber de alcanzar la denominada "verdad material" es propia de un sistema inquisitivo, al que el autor también denomina autoritario o de oficialidad, mientras que el sistema dispositivo, liberal o garantista, en palabras del autor, se identifica por el hecho de que un juez, independiente e imparcial, observa y juzga desde una posición de superioridad, asumiendo las partes las cargas de alegación y prueba, así como las consecuencias de cualquier deficiencia en el planteamiento del pleito y de cualquier insuficiencia probatoria ${ }^{5}$.

Ahora bien, tal y como advierte Bonet Navarro ${ }^{6}$, aunque puedan legítimamente mantenerse opiniones con base ideológica, es conveniente tratar de abordar la cuestión de los poderes del juez desde postulados técnicos, atendiendo a las ventajas e inconvenientes que ofrece cada posición, desde el punto de vista de obtener una tutela judicial de mayor calidad y una protección superior de los derechos de las personas.

Pues bien, precisamente, desde una perspectiva técnica, centrada en mejorar la calidad de la tutela jurisdiccional y en proteger, de la forma más eficaz posible, los derechos de las personas, resulta imprescindible, a la hora de determinar qué poderes ha de ostentar el juez civil, atender a la heterogeneidad de los derechos e intereses cuya tutela pide ante los tribunales civiles, algunos de los cuales no son estrictamente privados.

Más allá de cuestiones terminológicas, a las que me referiré más adelante, aunque ya avanzo que solo en la medida estrictamente necesaria para el propósito de esta contribución, la irrupción de estos derechos de grupo en la justicia civil se explica por el desarrollo de una serie de fenómenos sociales, económicos y culturales, más o menos entrelazados, entre los que cabe destacar el desarrollo del Estado social, por una parte, junto con el fenómeno del consumo y la contratación en masa, por otro 7 .

\footnotetext{
${ }^{3}$ VÁzQUEZ (2009), p. 37.

${ }^{4}$ Montero (2012), pp. 507-531, especialmente, pp. 529-530.

5 Parece claro que el uso del término "autoritario" para referirse a un sistema en el que el juez tiene poderes probatorios, frente al uso del término "liberal o garantista" para referirse a aquel en el que el juez se ve privado de tales poderes no es en absoluto neutral, apreciación que es realizada, entre otros autores por TARUFFO (2006), pp. 451-482.

${ }^{6}$ BOnet (2009), pp. 66-67.

7 La interrelación entre estos fenómenos y la aparición de nuevos conflictos metaindividuales es puesta de manifiesto, entre muchos otros autores, por Pellegrini (2014a), pp. 39-40.
} 
El desarrollo del Estado como prestador de servicios, el consumo de masas y el imparable avance de las nuevas tecnologías de la sociedad de la información y la comunicación trae consigo nuevos riesgos y problemáticas de alcance colectivo. Accidentes, incumplimientos, daños y conflictos masivos demandan una respuesta acorde con su naturaleza colectiva, mientras que, al mismo tiempo, a nivel sociológico, se promueve el cultivo de la conciencia colectiva o de grupo para aunar fuerzas en la tutela de los derechos de clase.

Además, de la mano de las señaladas transformaciones sociales, han surgido, así mismo, nuevas generaciones de derechos fundamentales que, poco a poco, se han ido reconociendo en las normas y textos constitucionales y que, paralelamente, han ido demandando mayores protecciones y garantías en todos los ámbitos, incluido el jurisdiccional. Así pues, con el desarrollo de los derechos de segunda generación, los conocidos como derechos sociales, económicos y culturales, los de tercera generación, denominados derechos de solidaridad o de los pueblos, y los de cuarta generación, vinculados con el acceso a las nuevas tecnologías, se ha ido consolidando un patrimonio jurídico, de titularidad colectiva, cuya tutela encuentra dificultades para encajar en las estructuras del proceso civil clásico, concebidas exclusivamente para la protección de bienes y derechos privados de titularidad individual ${ }^{8}$.

La amplia disparidad terminológica que se da en este ámbito de los derechos colectivos impide recoger, de forma exhaustiva, las distintas posturas doctrinales en este trabajo. Ahora bien, a efectos de poder avanzar en la exposición, es necesario aclarar la terminología que se empleará. Así pues, siguiendo, en este punto, a Bujosa Vadell, en las siguientes líneas se usará el término "intereses de grupo", para hacer referencia a los distintos tipos de intereses con trascendencia colectiva, tanto si en el fondo suponen verdaderas posiciones individuales necesitadas de protección supraindividual, como si implican relaciones más difuminadas entre el miembro del grupo y el bien jurídico indivisible ${ }^{9}$.

Dentro de los intereses de grupo, se distinguirán los intereses individuales homogéneos o pluriindividuales de los que denominaré supraindividuales. Los primeros, son aquellos derechos subjetivos individuales, provenientes de un origen común, normalmente un mismo hecho dañoso o conducta ilícita,

${ }^{8}$ En este sentido, tal y como apunta BujosA (2007), p. 602, la proclamación constitucional, contenida en el art. 9.2 de la Constitución Española, reconociendo al más alto nivel la dimensión social del hombre, choca con normas todavía basadas en la concepción liberal decimonónica del proceso.

${ }^{9}$ Bujosa (2007), p. 603. 
caracterizados por ser bienes divisibles y susceptibles de apropiación individual. Frente a estos, los supraindividuales son derechos de naturaleza indivisible, que pertenecen a un grupo, categoría o clase de personas, sin que por su propia naturaleza puedan ser objeto de apropiación exclusiva por ninguno de los miembros de tal grupo, categoría o clase, de tal forma que, respecto de estos el individuo sería únicamente titular mediato, siendo el titular directo la colectividad $^{10}$. Un ejemplo de derechos pluriindividuales se daría en el caso de que se hubiera comercializado un determinado alimento en mal estado, que hubiese provocado daños en la salud de un conjunto más o menos determinado de individuos, siendo la salud de cada particular un derecho propio e individual. Por su parte, el medio ambiente, los derechos generales de los consumidores o la no discriminación por razón de sexo, serían ejemplos de derechos supraindividuales, en tanto que indivisibles o no susceptibles de apropiación individual.

La irrupción de estos intereses de grupo, y su consolidación como auténticos derechos, conduce a la superación del concepto de derecho subjetivo, concebido, en términos generales, como poder jurídico del individuo ${ }^{11}$, o como facultad del sujeto concedida por una norma ${ }^{12}$ y destinada a satisfacer intereses propios $^{13}$. En este sentido, se afirma que "la litis individual va cediendo terreno frente a la necesidad de brindar tutela a nuevos intereses en los cuales son grupos o categorías completas de personas los que resultan involucrados ${ }^{\prime 14}$.

\section{De la tutela individual a la tutela colectiva}

Con la consolidación de los derechos de grupo, desde la perspectiva procesal, surge la necesidad de contar con mecanismos de tutela judicial efectiva para su protección, en la línea con lo prescrito por el art. 7.3 de la Ley Orgánica 5/1985, de 1 de julio, del Poder Judicial, al disponer que "Los Juzgados y

\footnotetext{
10 Esta terminología es la empleada por GASCÓN (2010), p. 18; La misma clasificación es realizada por BujosA (2007), pp. 605-606, que reconoce su importancia desde la perspectiva procesal (BujosA (2007), p. 610), aunque sin emplear la terminología de intereses pluriindividuales y supraindividuales que usaremos de aquí en adelante. El autor se refiere a ellos, respectivamente, como intereses individuales homogéneos e intereses de grupo en sentido estricto (BujosA (2007), p. 650); igualmente, el Código Modelo habla en estos términos de derechos individuales homogéneos frente a los que denomina derechos difusos, término que hemos preferido evitar, por ser usado en la LEC con otra acepción.

11 Díez-Picazo y Gullón (1988), p. 425.

12 Gallego (1996), p. 125.

13 Lasarte (2007), p. 121.

14 Palomo (2003), p. 191.
} 
Tribunales protegerán los derechos e intereses legítimos, tanto individuales como colectivos, sin que en ningún caso pueda producirse indefensión".

Así pues, resulta evidente que intereses supraindividuales y pluriindividuales demandan una tutela procesal colectiva, pero lo cierto es que esa demanda no responde a las mismas razones en el caso de unos y otros. En este sentido, como señala Barbosa Moreira, de forma muy expresiva, ocurre que los intereses aquí denominados supraindividuales son intereses esencialmente colectivos, en tanto que los intereses individuales homogéneos sólo son intereses accidentalmente colectivos ${ }^{15}$.

Así pues, en relación con los intereses supraindividuales, al no existir titulares individuales de los intereses en juego, que pertenecen a una colectividad de forma indivisa, el proceso tradicional, entendido como forma de tutela del interés subjetivo, choca con esa situación de supraindividualidad. No habría a priori ningún sujeto directamente legitimado para hacer valer tal derecho, en tanto que no pertenece a nadie, al ser la colectividad su único titular directo e inmediato. Además, su naturaleza indivisible se traducirá ope legis en una tutela jurídica con efectos ultra partes, de tal forma que su defensa en juicio supondrá, indefectiblemente, la defensa de todo el colectivo de interesados ${ }^{16}$.

Por el contrario, en el caso de los intereses pluriindividuales o individuales homogéneos, la tutela colectiva no es una exigencia impuesta por la naturaleza del derecho a proteger, sino más bien una opción que atiende, por una parte, a razones pragmáticas, de economía procesal y de eficiencia, evitando la multiplicación de demandas y procesos por el mismo hecho y previniendo el consiguiente riesgo de resoluciones contradictorias y, por otra, a razones de corte axiológico o dogmático, como el favorecimiento del derecho de acceso a la jurisdicción de los consumidores y usuarios, el principio pro actione y la tutela judicial efectiva de los perjudicados en masa.

En el ámbito del derecho del consumo ocurre, en ocasiones, que la colectivización de la tutela jurisdiccional funciona, en la práctica, como garantía de la tutela judicial efectiva de los consumidores, en tanto que la envergadura de los daños, individualmente considerados, es tan pequeña que la reclamación individual resulta antieconómica. En estos casos, aunque, formalmente, existe la posibilidad de demandar a título individual, los obstáculos materiales, relacionados, básicamente, con el coste en términos de tiempo y dinero, hacen que el mecanismo de la tutela colectiva se presente casi como una exigencia

15 Barbosa (1984), p. 196.

16 Bujosa (2007), p. 644. 
del derecho de acceso a los tribunales. En este sentido, la tutela colectiva viene a salvaguardar el derecho a la tutela judicial efectiva de los consumidores que sufren daños de bagatela, desempeñando una evidente función resarcitoria para los titulares de esos derechos individuales homogéneos ${ }^{17}$.

Al mismo tiempo, en los casos de daños de bagatela producidos en masa, la inexistencia de un adecuado mecanismo de tutela colectiva puede redundar en la impunidad del sujeto que ha causado el daño. Consecuentemente, las acciones colectivas despliegan, en este sentido, una función socio-preventiva ${ }^{18}$, ya que, de no existir posibilidad de tutela colectiva, la ausencia de reacción por parte de los consumidores podría redundar en una situación de incumplimiento generalizado de las normas de protección de ese colectivo por parte de los profesionales ${ }^{19}$.

Pues bien, constatada la necesidad de contar con mecanismos de tutela colectiva de los derechos supraindividuales y pluriindividuales, cabe preguntarse en qué medida deben de continuar vigentes los principios del proceso civil tradicional en los procesos colectivos. Pero, a tal fin, previamente, es necesario realizar una breve caracterización de la tutela colectiva, tratando de hacer abstracción de la regulación específica de los distintos ordenamientos jurídicos.

\section{Las características y principios informadores de los procesos colectivos}

Tal y como señala Gascón Inchausti, "la concreta configuración legal de las acciones colectivas como herramientas para la tutela de derechos e intereses plurales varía (...) de un ordenamiento a otro, pero presentan como rasgo común que ofrecen la posibilidad de resolver en un solo proceso y con una sola sentencia un conflicto que afecta a los derechos o intereses de una colectividad o de una pluralidad homogénea de sujetos, sin necesidad de que todos ellos participen activamente en ese proceso, pero previendo que todos ellos puedan beneficiarse, en su caso, de los efectos de una resolución favorable $e^{\prime 20}$.

De la precedente definición cabe extraer que una de las principales características de una acción colectiva radica en la legitimación extraordinaria,

\footnotetext{
17 Como apunta Bujosa (2007), p. 608, estamos, en este caso, ante la agregación de situaciones jurídico subjetivas individuales que se unen para mejorar las perspectivas de tutela.

18 Carballo (2009), p. 21.

${ }^{19}$ Con estas palabras se refiere GAsCón (2010), p. 17, a los peligros que se derivarían de la "pasividad en la defensa jurisdiccional" de los derechos de los consumidores.

${ }^{20}$ GASCÓN (2010), p. 17.
} 
por sustitución, que se atribuye, por disposición legal, a ciertas personas u organizaciones para actuar en el proceso, afectando, con su conducción procesal, a un grupo o colectivo más o menos determinado. Esto es así, al menos en relación con los intereses pluriindividuales o individuales homogéneos, cuando, por disposición legal, se legitima a determinadas asociaciones o entidades para actuar procesalmente en nombre del grupo. Por el contrario, cuando se trata de intereses supraindividuales, hay quien sostiene que se trataría de una legitimación ordinaria sui generis, actuando la entidad legitimada como gestora autónoma del interés colectivo ${ }^{21}$.

El tema de la legitimación es realmente complejo y en el panorama comparado existen regulaciones muy heterogéneas ${ }^{22}$. Pero cabe señalar que lo verdaderamente específico y común a las acciones colectivas es que quien actúa procesalmente como demandante no es titular del derecho en liza, o al menos no es titular exclusivo del mismo.

Derivado de lo anterior, aparece la segunda principal característica de las acciones colectivas, que se encuentra en la posible extensión subjetiva de los efectos de la resolución que ponga fin al proceso colectivo a todos los miembros del grupo o clase, independientemente de que hayan intervenido en el proceso o no. Aquí radica la gran potencialidad de las acciones colectivas, en tanto que instrumentos útiles para resolver, en un mismo proceso y a través de una única resolución, un conflicto de base subjetiva amplia, evitando la multiplicación de litigios basados en los mismos hechos ${ }^{23}$.

Así pues, las acciones colectivas se caracterizan por la extensión a terceros de los efectos de la resolución que ponga fin al proceso, vinculando a aqueIlos sujetos que, encontrándose en un situación jurídico-material idéntica o análoga a la de las partes procesales, hayan manifestado su voluntad de vincularse al proceso colectivo, cuando se trate de un sistema opt-in, o no hayan manifestado expresamente su voluntad de quedar excluidos de los resultados del proceso, cuando se establezca un sistema opt-out ${ }^{24}$.

\footnotetext{
21 Bujosa (2007), p. 642.

${ }^{22}$ Un estudio comparado sobre esta cuestión, donde se refieren las regulaciones de varios países de América Latina (concretamente de Argentina, Brasil, Chile, Colombia, México y Uruguay) puede verse en Ovalle (2013), pp. 1057-1092.

23 GASCÓN (2010), p. 27.

24 En el panorama comparado, como ejemplos de sistemas opt-in, encontramos la mayor parte de los sistemas europeos, por ejemplo, y sin ánimo de exhaustividad, estarían en este grupo Italia, Alemania, Gran Bretaña, Francia o Suecia, mientras que, como ejemplos de sistemas opt-out, encontramos el sistema norteamericano de class actions y otros claramente influenciados por aquel como el de Brasil o el contenido en el Código Modelo, así como los sistemas de España, Holanda y Portugal.
} 
Llegados a este punto, cabe plantearse lo que constituye el objeto principal de este trabajo, esto es, si las especificidades de la tutela colectiva, justifican la erosión de los principios que informan el proceso civil y, concretamente, si requieren la atribución de especiales poderes al juez. En este sentido, la experiencia comparada muestra que, incluso en procesos civiles considerados "liberales", como podría ser el estadounidense, en las acciones colectivas, se justifica atribuir al juez amplios poderes de control sobre la actuación de las partes ${ }^{25}$. Estos poderes no se limitan, como podría pensarse, a la dirección formal e impulso del proceso, sino que se extienden a la iniciativa probatoria e, incluso, a la determinación del objeto del proceso, facultades tradicionalmente atribuidas a las partes.

Es por eso que, en las siguientes líneas, se tratará de determinar por qué motivo y en qué medida los principios clásicos de los procesos civiles denominados "liberales" se ven erosionados en los procesos colectivos. Y si, efectivamente, razones técnicas de mayor calidad de la justicia y mejor protección de los derechos de los justiciables justifican estas matizaciones.

\section{Los principios procesales informadores de la tutela colectiva}

Así pues, a continuación se analizará la vigencia de ciertos principios procesales fundamentales, como el de igualdad de armas, de audiencia y contradicción, para ver cómo actúan en el proceso colectivo y si, dadas las especificidades de estos procesos, demandan o admiten alguna matización. Posteriormente, se centrará el análisis en el principio dispositivo, para ver si tiene efectiva aplicación a estos procesos o si, por el contrario, la dimensión social de los mismos conduce a desnaturalizarlo.

Con evidente ánimo de prejuzgar, cabe poner de relieve, ya en este instante, que mientras algunos de estos principios, concretamente, el de igualdad de armas y el de audiencia o contradicción, son principios estructurales del proceso ${ }^{26}$, esencialmente irrenunciables, dada su vinculación con el derecho de defensa, por el contrario, el principio dispositivo, respetando ciertos límites derivados de la posición institucional que corresponde al juzgador y de los derechos fundamentales de las partes, no tiene carácter necesario, sino que más bien responde a una opción legislativa, a veces técnico-jurídica, a

\footnotetext{
Una sintética y clarificadora referencia a las ventajas e inconvenientes que presentan cada uno de estos dos sistemas puede verse en ARMENTA (2013 b), pp. 83-86.

${ }^{25}$ Weinstein y Merger (1975), pp. 614-616.

${ }^{26}$ Gimeno (1981), pp. 181-187; también denominados por la doctrina jurídico-naturales (De LA Oliva et al. (2007), p. 51) o principios básicos de la justicia natural (Pérez-Cruz (2015), p. 395).
} 
veces de carácter más bien político, pero, en cualquier caso, susceptible de matices y excepciones.

\subsection{El principio de igualdad de armas}

Desde la perspectiva de la igualdad, a primera vista, podría pensarse que, en ciertos procesos colectivos, por ejemplo, los vinculados al derecho del consumo, en los que se enfrentan empresarios y profesionales con consumidores y usuarios, está justificada una cierta protección de la parte débil, en este caso, del consumidor.

De hecho, se acepta generalmente que las acciones colectivas en materia de consumo sirven, precisamente, para reequilibrar las fuerzas en favor de los consumidores, facilitando su acceso a los tribunales a través de la colectivización de la tutela judicial de sus derechos e, incluso, a través de la institucionalización de su defensa, por medio de la atribución de legitimación para actuar en su nombre a organizaciones o entidades especializadas en Derecho de consumo, que cuentan con fondos propios para financiar la defensa de sus derechos ante los tribunales. En este sentido, tal y como sostiene Carballo Piñeiro, la necesidad de las acciones colectivas surge de forma correlativa al "desarrollo de la noción de parte débil, esto es, de la existencia de posiciones de desventaja estructural, que precisan de mecanismos específicos que permitan la equiparación de posiciones" ${ }^{\prime 27}$.

Ahora bien, lo que el principio de igualdad de armas demanda es una razonable igualdad de posibilidades en el ejercicio de la acción y la defen$\mathrm{sa}^{28}$. Por lo tanto, más allá del hecho de que las acciones colectivas, puedan servir, en ocasiones, como instrumento para superar barreras u obstáculos a la igualdad real o material entre las partes, lo que determinará el escrupuloso respeto a este ineludible principio procesal es que, a lo largo del proceso, demandante y demandado tengan análogas posibilidades de alegación, prueba e impugnación.

Es por eso que los principales riesgos de vulneración del principio de igualdad en las acciones colectivas, no se derivan de la desigualdad material entre las partes, sino, más bien, del peligro de que un juez, excesivamente comprometido con la defensa de los miembros ausentes del grupo, favorezca la posición procesal de este frente a la del demandado.

Por lo tanto, es preciso advertir ya, desde este momento inicial, que los mayores poderes que creo que debieran atribuirse al juez en las acciones

27 Carballo (2009), p. 18.

${ }^{28}$ Couture (1997), p. 185. 
colectivas por los motivos que luego se dirán, encuentran como límite infranqueable, por un lado, la imparcialidad del juzgador y, por otro, el respeto a la igualdad formal entre las partes procesales ${ }^{29}$. Por lo tanto, cuando se indica, por ejemplo, que el juez debe garantizar el respeto a los derechos de los miembros del grupo ausentes, esto no puede ser entendido de forma que el juzgador se erija en defensor de los derechos del grupo o colectivo, aunque se le atribuyan facultades de control sobre la adecuación de la actuación del demandante en tanto que valedor de aquellos.

\subsection{Los principios de audiencia y contradicción}

El principio de contradicción alude a que el proceso tiene una construcción dialéctica y en el debate judicial las dos partes deben ser oídas ${ }^{30}$. En los procesos colectivos ocurre que si se centra el análisis en las partes formales, esto es, en quien actúa en calidad de demandante y quien resulta demandado, no parece que tales máximas sufran erosión alguna. Tanto el demandante como el demandado tendrán la posibilidad de ser oídos en el proceso, con oportunidades análogas para contradecir las alegaciones y pruebas que se presenten de contrario, de tal forma que la sentencia que llegue a dictarse sea el resultado de ese debate contradictorio, desarrollado en condiciones de igualdad.

Ahora bien, si se toma en consideración que el resultado del proceso colectivo afectará a terceros que no han intervenido en el mismo, entonces hay que asumir que, en estos procesos, los principios de audiencia y contradicción se interpretarán, necesariamente, de forma parcialmente diversa a como se entienden de ordinario en el proceso civil. En este sentido, Armenta Deu señala que el principio audiatur et altera pars "resulta excepcionado cuando se extiende la cosa juzgada a terceros que no participaron, no pudieron hacerlo o incluso ignoraron la existencia del repetido proceso ${ }^{131}$. Sobre todo en sistemas opt-out, los riesgos para los principios de audiencia y contradicción no son en absoluto desdeñables.

\footnotetext{
${ }^{29}$ En esta sentido, VÁzQuez (2001), p. 122, advierte de que sería un error pretender corregir el reflejo en el proceso de las desigualdades entre los litigantes a base de conceder a la parte que se supone débil privilegios negados a la contraria y menos aumentando los poderes de oficio del juez en favor del débil, con peligro evidente para la imparcialidad judicial.

${ }^{30}$ VÁzQuez (2001), p. 118.

31 Armenta (2013 b), p. 66; también Palomo (2003) p. 199, se refiere a la necesidad de relajar los principios tradicionales de la litigación, entre ellos el principio de audiencia, ante la imposibilidad de citar a todos y cada uno de los afectados por la lesión a un bien supraindividual como el ambiente.
} 
Resulta evidente que los miembros de ese colectivo o grupo que no se personen en el proceso no serán efectivamente oídos, lo cual puede resultar problemático en el caso de intereses individuales homogéneos, en tanto que se produce una afectación directa de los derechos subjetivos de los afectados.

Esta situación es asumible siempre y cuando, a tales sujetos, se les haya ofrecido una posibilidad real y efectiva de intervenir en el proceso, en su caso, para manifestar su voluntad de desvincularse de su resultado. Y es que, en el proceso civil, al contrario de lo que sucede ordinariamente en el penal, basta con darle a la parte la oportunidad de ser oída, sin que deba serlo efectivamente. Ahora bien, si no han tenido tal posibilidad, no podrían quedar vinculados al resultado del proceso colectivo, sin perjuicio de que puedan beneficiarse de él si así lo desean ${ }^{32}$. Y es que, en este sentido, cabe afirmar que un sistema de tutela colectiva en el que no se permita a los titulares individuales participar en el proceso y desvincularse de él, no sería respetuoso con el principio de audiencia y contradicción, vulnerando, por lo tanto, las garantías del debido proceso ${ }^{33}$.

La asistemática y fragmentaria regulación española sobre los procesos colectivos, en este punto, como en tantos otros, adolece de una importante laguna, en tanto que se establece un sistema opt-out, que no exige adhesión de cada interesado para quedar vinculado al resultado del proceso, pero, sin embargo, el legislador no ha previsto expresamente ninguna forma de desvinculación de los titulares individuales, respecto del resultado del proceso colectivo. Esta situación es realmente grave si se observa que el art. 222.3 LECiv extiende los efectos de la cosa juzgada, derivados de la resolución que ponga fin al proceso colectivo, a los consumidores y usuarios, titulares de los derechos en liza, incluso si tal resolución es desestimatoria.

Para salvar los problemas de orden constitucional que presenta una regulación legal de estas características, Gascón Inchausti entiende que el derecho de exclusión tiene que ser uno de los contenidos posibles de la intervención del consumidor a título individual en el proceso colectivo ${ }^{34}$. Sin embargo, esto no parece suficiente, especialmente, en los casos en que no es posible asegurar

\footnotetext{
32 En este sentido, tal y como apunta CAPELETtı (1975), c. 55, es una exigencia de la justicia natural y constitucional que cada sujeto partícipe en la relación deducida en juicio tenga una efectiva oportunidad de contradicción, sin la cual la sentencia no podría afectarle.

33 LÓPEZ (2011), pp. 62-63.

${ }^{34}$ GaSCÓn (2010), p. 127.
} 
que todos los miembros del grupo han tenido un conocimiento efectivo del proceso, por tratarse de un grupo indeterminado o de difícil determinación ${ }^{35}$.

El problema más grave se plantea, a mi juicio, en aquellos supuestos de defensa de intereses individuales homogéneos en grupos indeterminados. Por ejemplo, en el caso de que se haya comercializado un medicamento que se dispensaba sin receta médica y que fuera perjudicial para la salud. No habría manera, a priori, de saber quiénes habrían consumido el medicamento ni, evidentemente, de notificar personalmente a cada uno de los afectados la pendencia del proceso. En un asunto de estas características, aunque se podría realizar una campaña en medios de comunicación, haciendo un Ilamamiento a los perjudicados, no se podría impedir que, finalizado el proceso colectivo, cualquier perjudicado que no hubiese acudido al Ilamamiento litigase individualmente $y$, desde luego, se le produciría una clara indefensión si se le obligase a asumir una sentencia desfavorable.

A la misma solución conduce la sentencia del Tribunal Supremo español 13/2017, de 24 de febrero, en la cual, en aplicación de la doctrina del Tribunal de Justicia de la Unión Europea contenida en la sentencia de 14 de abril de 2016 (asuntos acumulados C-381/14 y C-385/14), el Tribunal Supremo excluye la apreciación de cosa juzgada entre una acción colectiva y una acción individual, en tanto que, según su parecer, unas y otras tendrían objetos y efectos jurídicos distintos. Consecuentemente, la desestimación de la acción colectiva sólo impediría el planteamiento de una ulterior acción colectiva por los mismos hechos, pero no de acciones individuales de quienes no intervinieron en el proceso colectivo.

Lo dicho hasta ahora resulta de aplicación a aquellos supuestos en los que el litigio se refiere a derechos individuales homogéneos, en tanto que los titulares de tales derechos podrían optar por litigar individualmente. Sin embargo, en los procesos en los que se tutelen, exclusivamente, derechos supraindividuales, es decir, aquellos que pertenecen indivisiblemente a una

\footnotetext{
35 En cuanto a las formas de comunicación de la pendencia del proceso a los miembros del grupo, la LECiv distingue dos supuestos, atendiendo la determinabilidad del colectivo afectado. El primer supuesto, se refiere a un grupo cuyos miembros están determinados o resultan fácilmente determinables, caso en el que se exige la efectiva comunicación previa a todos los interesados (art. 15.2 LECiv). El segundo supuesto legal, se refiere al caso en que los miembros del grupo sean indeterminados o de difícil determinación, disponiendo, en tal circunstancia, la realización de un Ilamamiento público, que suspenderá el curso del proceso por un plazo máximo de dos meses (art. 15.3 LECiv), transcurrido el cual no se admitirán personaciones individuales, sin perjuicio de que, quienes se vean beneficiados por la resolución, puedan, en fase de ejecución, hacer efectivos sus derechos.
} 
colectividad, no parece imprescindible dar una efectiva oportunidad de ser oído a todos los miembros de ese colectivo difuso ${ }^{36}$. Los interesados podrían, en su caso, trasladar sus alegaciones o, incluso, aportar elementos de convicción que tengan en su poder, a través de las entidades legitimadas para el ejercicio de estas acciones, interesando una determinada actuación procesal o, incluso, la personación en el proceso de un organismo legitimado para la defensa del interés supraindividual en liza para, de esta forma, suplir o complementar la actuación del ente inicialmente demandante.

Esta limitación del principio de audiencia, para esos terceros que no son partes formales, pero que tienen un interés más o menos directo en el resultado del pleito, resulta admisible en el caso de los intereses supraindividuales, en tanto en cuanto ninguna persona podría, individualmente, pedir la tutela del bien jurídico supraindividual, con lo que esta solución no restringe su derecho a tutelar jurisdiccionalmente sus legítimos intereses, que quedan suficientemente garantizados con la actuación de los legítimos demandantes y, en su caso, con un cierto control de su actuación por parte del juez o de algún otro organismo público como, por ejemplo, el Ministerio Fiscal.

Por su parte, el Código Modelo establece un sistema de cosa juzgada secundum eventum litis para los procesos sobre derechos individuales homogéneos, de forma que si la pretensión colectiva es rechazada, los interesados podrán accionar individualmente (art. $33^{\circ}$ párr. $2^{\circ}$ ). Por el contrario, para los derechos supraindividuales, esto es, los no susceptibles de apropiación individual, se establece un sistema secundum eventum probationem, de tal forma que una segunda acción colectiva podrá volver a plantearse si la primera se desestimó por falta de pruebas. Además, el juez ordenará la publicación de edictos para que los interesados puedan intervenir en el proceso como asistentes o coadyuvantes (art. 21 Código Modelo).

En cualquier caso, no hay que olvidar que el principio de audiencia, al igual que el de igualdad de armas, es un principio de los denominados jurídico-naturales, sin los cuales no habrá un verdadero proceso, sino a lo sumo apariencia de proceso. Por consiguiente, sea cual sea el sistema de tutela colectiva por el que se opte, se deberá respetar el derecho a ser oído de todos aquellos que sostengan un interés legítimo en el resultado del pleito.

Por otra parte, cualquier actuación de oficio del juzgador, ya en lo que se refiere a la dirección del proceso, ya en materia probatoria, cuando así lo

\footnotetext{
${ }^{36}$ Como observa, Bujosa (2007), p. 655, la naturaleza de estas pretensiones hace más innecesaria la intervención individual de los consumidores y usuarios en estos proceso, en comparación con aquellos en los que se discuten pretensiones realmente individuales.
} 
permita la legislación, debe de tener como límite, en todo caso, el debido respeto a los principios de igualdad, contradicción y audiencia, instrumentales del más amplio e irrenunciable derecho fundamental a la defensa. Así pues, aunque en una visión más tradicional del principio contradictorio, las decisiones de oficio no quedaban vinculadas a este tamiz adversarial, resulta obligado afirmar que el incremento de los poderes de dirección material del juzgador ha de acompañarse de una reinterpretación de aquel principio ${ }^{37}$.

\subsection{El principio dispositivo}

Ahora bien, si hay un principio que realmente debiera sufrir matizaciones en los procesos colectivos, ese es el principio dispositivo.

En la LECiv, el principio dispositivo se manifiesta a lo largo de todo el proceso con gran intensidad, tanto en su forma de iniciación, que depende de la libre voluntad del titular del derecho, como en su libre terminación, en cualquier momento, a través de actos tales como la renuncia, el desistimiento, el allanamiento o la transacción. Así mismo, este principio se refleja en la determinación del objeto del proceso por las partes y en las limitadas posibilidades del juzgador en la dirección material del mismo, correspondiendo a las partes el impulso procesal, la aportación de los hechos y la iniciativa probatoria, quedando limitada la apreciación de oficio por parte del juzgador a constatar la ausencia de presupuestos procesales y, en su caso, a decidir sobre la inadmisión de la demanda, si bien sólo en aquellos casos en que concurra alguna de las causas tasadas de inadmisión.

En contraposición se observa que, en la regulación contenida en el Código Modelo de acciones colectivas, los poderes del juez son muy amplios, desde luego más que en un proceso civil tradicional, y, correlativamente, los poderes de las partes para disponer del objeto del proceso sufren serias limitaciones ${ }^{38}$.

\footnotetext{
${ }^{37}$ En este sentido, resulta de interés la denominada prohibición de la decisión-sorpresa, regulada por el Código Procesal Civil brasileño en el art. 10. Según Zufelato (2017), p. 25, esta prohibición no es más que una dimensión del principio de contradicción, según el cual las partes no pueden ser sorprendidas por una decisión respecto a una cuestión que no ha sido expresa y previamente discutida, incluyendo lo referente a las tradicionales materias de conocimiento de oficio

38 Igualmente, si se acude a la regulación de las class action americanas Ilaman la atención las amplias facultades del juez a la hora de admitir la tramitación de la demanda como colectiva, de valorar la representatividad del demandante y la adecuación de su abogado, de determinar el objeto de la acción colectiva, de ponerle fin en determinadas circunstancias y, sobre todo, de controlar la adecuación del contenido de los acuerdos que las partes pueden alcanzar una vez iniciado el proceso, o de forma previa, requiriéndose, en todo caso, su homologación judicial.
} 
Pues bien, a continuación, se tratarán de determinar las causas que justifican la limitación de este principio en las acciones colectivas para, posteriormente, contraponer aquello que establece al respecto el sistema de tutela colectiva del Código Modelo, frente a la situación de la LECiv que, carente de un auténtico "sistema" de acciones colectivas, se conforma con introducir en un código procesal civil de corte esencialmente individualista una decena de normas para la tutela de intereses colectivos y difusos, lo cual resulta, a todas luces, insuficiente.

\subsection{1. ¿Por qué limitar el principio dispositivo en los procesos colectivos?}

El principio dispositivo "se apoya sobre la suposición (...) de que en aqueIlos asuntos en los cuales sólo se dilucida un interés privado, los órganos del poder público no deben ir más allá de lo que deseen los propios particulares", resultando que, por el contrario, en aquellos casos en que se ve comprometido un interés social no será lícito para las partes contener la actividad de los órganos del poder público ${ }^{39}$.

Tal y como indica Vázquez Sotelo, el fundamento del principio dispositivo se encuentra en la esencia misma del derecho subjetivo, que consiste en su pertenencia a un titular, siendo característico de esa relación de titularidad, precisamente, que sólo quien es titular puede deducir el derecho en juicio ${ }^{40}$. En una línea similar, sostiene Montero Aroca que, "en el proceso civil, el interés que la parte solicita que sea protegido o tutelado por el órgano jurisdiccional es el privado, siendo preponderante en él la autonomía de la voluntad. El titular de ese derecho es el individuo, no la sociedad y, por tanto se trata de un derecho o interés disponible ${ }^{\prime \prime 4}$.

Sin embargo, no cabe desconocer que, a día de hoy, junto con el derecho subjetivo de carácter estrictamente privado, han ido surgiendo otros derechos o intereses, de naturaleza supraindividual, cuyas características los sitúan a medio camino entre el interés público y el privado, presentando su reconocimiento y tutela jurisdiccional una clara dimensión social ${ }^{42}$. La difuminación de las fronteras entre lo público y lo privado, que se produce al tratar de indagar

39 Couture (1997), p. 186.

40 VÁzQuez (2001), p. 123.

41 Montero (2012), pp. 513-514.

42 Exposición de Motivos del Código Modelo de Procesos Colectivos para Iberoamérica. 
en la naturaleza de estos derechos ${ }^{43}$, inevitablemente, va a tener consecuencias en su forma de tutela ${ }^{44}$.

Así pues, la primera justificación para las matizaciones que ha de sufrir el, tantas veces, referido principio dispositivo, en las acciones colectivas, radica en el hecho de que en los procesos colectivos están en juego intereses semipúblicos. En este sentido, sostiene Armenta Deu que "las acciones colectivas constituyen el paradigma de una tendencia en la que la aparición de intereses no exclusivamente privados explica y justifica la creciente intervención del juez en el proceso civil"45. Por su parte, Bujosa Vadell señala que los derechos e intereses de grupo se posicionan entre los estrictamente individuales y los públicos o generales, cuestionándose si la relevancia colectiva de tales intereses va a alterar la dicotomía entre los principios de necesidad y oportunidad, situándonos en una especie de procesos civiles inquisitorios o necesarios ${ }^{46}$.

La especial situación de estos derechos se pone de manifiesto, paradigmáticamente, en el Código Modelo iberoamericano, cuando señala que el primer requisito que deberá valorar el juez para admitir a trámite una acción colectiva es la relevancia social de la tutela invocada, midiéndose tal preeminencia en función de la naturaleza del bien jurídico afectado, de las características de la lesión o del elevado número de personas perjudicadas (art. $2^{\circ} \mathrm{II}$ ).

La relevancia social de los bienes en juego se aprecia, no solo en el caso de intereses supraindividuales, en los que parece más evidente, dada su mayor cercanía con los intereses generales, sino también cuando se daña una multiplicidad de derechos individuales homogéneos. Así, por ejemplo, esta relevancia social se aprecia claramente cuando se pide el cese de una actuación empresarial que incumple una determinada normativa medioambiental

\footnotetext{
${ }^{43}$ En esta línea, apunta Bujosa (1995), p. 96, que la dificultad de determinar la naturaleza jurídica de los intereses de grupo se debe a la difuminación operada entre el Derecho Público y el Derecho Privado; Mientras que, LozAno-Higuero (1983), p. 73, indica que el término colectivo, entre otros, tales como general, social, institucional, bordean, aunque sólo sea semánticamente, los límites o fronteras de lo público.

${ }^{44}$ Según Palomo (2003), p. 195, es, precisamente, esa situación intermedia entre los intereses públicos y privados lo que juega en contra de la adecuada representación de los intereses colectivos, ya no son intereses puramente privados, de cuya tutela y defensa se hagan cargo sus titulares, ni un interés público, de cuya protección se ocupe el defensor del interés general.

45 Armenta (2013 a), p. 246.

${ }^{46}$ Bujosa (2015), p. 6; VÁzquez (2009), p. 51, sostiene que en lugar de usar la expresión de procesos civiles inquisitivos, resultaría más adecuado referirse a "procesos civiles sobre relaciones no disponibles".
} 
-siendo el medioambiente un interés típicamente supraindividual- ${ }^{47}$. Pero, también cuando se pretende el cese en la comercialización de contratos con cláusulas limitativas de la variabilidad de los intereses de hipoteca, por ser tales cláusulas consideradas abusivas, solicitando, además, la nulidad de las mismas y la condena al pago de las cantidades cobradas indebidamente al cliente-siendo las pretensiones de nulidad y cobro intereses individuales homogéneos-.

En el caso del medioambiente, el valor intrínseco del bien, la necesidad de institucionalizar su defensa y su relación con otros bienes o derechos fundamentales e irrenunciables, como puede ser la salud, ponen claramente de manifiesto su relevancia o preeminencia para la sociedad. Pero también en el segundo supuesto, relativo a una mala práctica comercial, aunque la afectación sea meramente patrimonial, existe esa relevancia social, en tanto que, en este caso, la tutela colectiva permite o facilita el acceso a la justicia de los miembros del grupo perjudicado, evita la multiplicación de demandas por hechos idénticos o análogos con el evidente riesgo de que se dicten sentencias contradictorias y, al mismo tiempo, despliega un efecto socio-preventivo, que previene que, en el futuro, la conducta ilícita o abusiva se repita.

La segunda razón clave para justificar las matizaciones al principio dispositivo en los procesos colectivos radica, no ya en la naturaleza o la relevancia social de los bienes o derechos objeto del proceso, sino en los efectos que del mismo se derivan. Dado que la resolución que pone fin a un proceso colectivo puede vincular a sujetos que no han sido parte en dicho juicio, se hace necesario establecer mecanismos que sirvan para velar por los intereses de esos terceros, de tal forma que su derecho de defensa se salvaguarde, como exigen las garantías del debido proceso y, más concretamente, los principios de audiencia y contradicción.

Es necesario establecer controles efectivos para que el demandante no actúe procesalmente de forma que perjudique los intereses de esos terceros, ya de mala fe, ya por negligencia. En este sentido, si se considera que los legitimados para ejercitar la acción colectiva, normalmente, no cuentan con el mandato ni la autorización de aquellos terceros que, posiblemente, quedarán vinculados por el resultado del proceso, parece que el control judicial deviene imprescindible para garantizar, no sólo el debido respeto a

\footnotetext{
47 Sobre la supraindividualidad inherente al medio ambiente, resultan interesantes las reflexiones de PALOMo (2003), p. 91, quien señala que se trata de "una nueva realidad sociológica, que deja atrás la situación tradicional de la litis individual que se centra entre un actor y un demandado, donde todo queda limitado a un interés singular, dentro de la legitimación también individual".
} 
los derechos procesales de los sujetos ausentes, sino también la integridad de sus derechos materiales.

Ahora bien, esta necesidad de proteger a los ausentes, tiene que ser entendida con cautela a la hora de justificar mayores poderes del juez civil, en tanto en cuanto no cabe olvidar que tales sujetos ausentes, aun sin ser formalmente partes, son interesados en el litigio, y el juez debe mantener, también respecto de ellos, la necesaria imparcialidad, de tal forma que, tal y como señala Bujosa Vadell, no deje de ser juez, para pasar a convertirse en abogado de los miembros ausentes del grupo o clase, lo cual resultaría inadmisible ${ }^{48}$.

La naturaleza supraindividual o el interés social que se protege con las acciones colectivas, junto con el hecho de que queden implicados, por su resultancia, terceros ajenos al proceso, podría, incluso, poner en entredicho la virtualidad de los conceptos de cargas y posibilidades para explicar el proceso colectivo. Así pues, siguiendo a Goldschmidt "una carga es un imperativo del propio interés", por lo que "no hay frente a ella derecho del adversario o del Estado. (...) En cambio, existe una relación estrecha entre las cargas procesales y las posibilidades, es decir, los derechos procesales de la misma parte, porque cada posibilidad impone a la parte la carga de aprovechar la posibilidad al objeto de prevenir su pérdida" ${ }^{49}$.

Pues bien, al litigar el demandante de una acción colectiva, sobre derechos ajenos, ya no cabe interpretar que lo que mueve su actuación en el proceso es exclusivamente el "imperativo de su propio interés", porque de sus posibilidades de actuación en el proceso, surgen auténticas obligaciones del demandante para con los miembros ausentes del grupo o clase. Resultando, además, que el juzgador, en su labor de garante de los derechos de las partes, ha de velar por la diligencia en la actuación del demandante. Con esta contraposición no se pretende, desde luego, criticar las nociones de carga y posibilidad, desarrolladas por Goldschmidt, como forma de explicar el proceso como situación jurídica, sino llamar la atención sobre la imposibilidad de trasladar de forma automática conceptos y principios procesales pensados para el proceso civil tradicional, caracterizado por el conflicto intersubjetivo subyacente que se da entre dos particulares, a la tutela colectiva, que escapa a la correspondencia básica entre la parte procesal y el que se presenta como titular del derecho.

${ }^{48}$ Bujosa (2015), p. 25.

49 Goldschmidt (1936), p. 84. 
En definitiva, los motivos que subyacen a las restricciones que sufre el principio dispositivo en los procesos colectivos se vinculan, por un lado, a la relevancia social e intrínseca indisponibilidad de algunos de los derechos o intereses que conforman su objeto $y$, por otro, al hecho de que en estos procesos se ventilen derechos de terceros. Tanto la naturaleza transindividual de los derechos e intereses en juego como la extensión de los efectos del proceso a terceros son dos cuestiones clave de la tutela colectiva que no deben de perderse de vista a la hora de analizar en qué se traduce la, tantas veces repetida, limitación del dispositivo.

\subsubsection{Los poderes del juez y las necesarias matizaciones de los principios dispositivo y de aportación de parte en los procesos colectivos}

Una vez justificada la necesidad de matizar el principio dispositivo en las acciones colectivas, es preciso determinar en qué se manifiesta, a lo largo del proceso, esta erosión a la libre disposición del objeto procesal por las partes, así como el necesario incremento de los poderes del juez.

Como se analizará, las restricciones a la libre autonomía de las partes procesales, junto con los más amplios poderes del juzgador, se observan en múltiples actuaciones procesales y a lo largo de todo el iter procesal: desde la interposición de la demanda y los controles a su admisibilidad hasta la finalización del proceso a través de acuerdo o transacción.

El nuevo papel que el juez debe de asumir en los procesos colectivos pasa por la ampliación de sus facultades, tanto de dirección formal como de dirección material del proceso. En cuanto a la dirección formal que, evidentemente, corresponde siempre al juzgador, sería adecuado dotarles de determinadas facultades que le permitieran introducir ciertas dosis de flexibilidad en sus decisiones ${ }^{50}$, siempre en pos de garantizar una tutela adecuada de los derechos en litigio, por ejemplo, ampliando los motivos de inadmisión de la demanda o las posibilidades de solicitar a las partes su subsanación, no solo por motivos de forma, sino también de fondo, referidos al planteamiento de la misma. Al mismo tiempo, sería conveniente incrementar las facultades judiciales de dirección material del proceso, de tal forma que, en determinados supuestos, el juez pudiese intervenir en la proposición de las pruebas.

\footnotetext{
50 En este sentido, resulta especialmente interesante el "principio de instrumentalidad de las formas" que según PelLeGrini (2014b), p. 399, se erige en principio general de los procesos colectivos, según el cual, observando el contradictorio y no habiendo perjuicio para la parte, las formas procesales deben de ser siempre flexibilizadas.
} 


\subsubsection{Legitimación legal del demandante y control judicial sobre su adecuada representatividad}

Según Vázquez Sotelo el principio dispositivo en sentido propio se funda en que los derechos e intereses legítimos de los particulares (...), como derivados del Derecho privado, tienen cada uno de ellos un titular, que es el único que puede solicitar la tutela judicial a través del proceso ${ }^{51}$. En la misma línea, afirma Pérez-Cruz Martín que "el principio dispositivo (...) viene referido a la disponibilidad que los litigantes tienen sobre el interés privado y sobre la conveniencia o no de acudir al órgano jurisdiccional pretendiendo su satisfacción" $n^{\prime 2}$.

Pues bien, en las acciones colectivas, se observa, primeramente, que la iniciativa de litigar ya no se residencia, o al menos no exclusivamente, en manos del titular del derecho, sino que se legitima a otros individuos o entidades para ejercitar la acción. Se produce así, salvando las distancias, una suerte de "expropiación del conflicto", similar a la que tiene lugar en el proceso penal, cuando se atribuye al Ministerio Fiscal el monopolio de la acusación en detrimento de la víctima del delito.

Si se considera que las acciones colectivas tienen, entre otras finalidades, la de facilitar el acceso a la justicia de aquellos que, individualmente no litigarían por resultar antieconómico, resulta totalmente comprensible el establecimiento de mecanismos de legitimación extraordinaria para permitir la colectivización de la defensa de sus derechos. Sin embargo, esto no es lo habitual en el proceso civil, configurado, como regla general, para la defensa de derechos propios por parte de su titular.

A propósito del tema de la legitimación en las acciones colectivas, se hace preciso distinguir el modelo alemán de la Verbandsklage del modelo propio de las class actions norteamericanas ${ }^{53}$. El modelo alemán se caracteriza por la legitimación atribuida a determinadas asociaciones autorizadas a tal fin por el Estado, mientras que, en el modelo estadounidense de class actions, los legitimados para actuar en nombre de la clase son los particulares, esto es, un individuo o un grupo de individuos, que deben de pertenecer a la clase y sostener pretensiones propias coincidentes con las de la clase (tipicality), además de ser considerados por el juez aptos para desarrollar una representación y defensa adecuada de los intereses de todos los miembros de la clase

\footnotetext{
51 VÁzQuez (2001), p. 123.

52 Pérez-Cruz (2015), p. 400.

53 Sobre esta distinción, véase TARuffo (2005), pp. 24-31.
} 
(adequacy of representation) $^{54}$. Al margen de la atribución de legitimación a los individuos o a determinadas organizaciones privadas, algunos ordenamientos jurídicos optan por atribuir legitimación, así mismo, a la iniciativa estatal, a través del Ministerio Fiscal o de ciertos organismos públicos.

La LECiv distingue, a efectos de legitimación, entre acciones para la defensa de intereses colectivos y difusos. Los colectivos, en terminología legal, serían aquellos en los que los perjudicados por un hecho dañoso son un grupo de consumidores o usuarios determinados o fácilmente determinables. En este caso, la legitimación para pretender su tutela correspondería a las asociaciones de consumidores y usuarios, a las entidades legalmente constituidas que tengan por objeto la defensa o protección de estos, así como al propio grupo de afectados, siempre que se constituya con la mayoría de sus miembros (arts. 11.2 y $6.7^{\circ}$ ). Por el contrario, en el caso de las acciones en defensa de intereses difusos, es decir, siendo los perjudicados por un hecho dañoso una pluralidad de consumidores o usuarios indeterminada o de difícil determinación, la legitimación para demandar en juicio correspondería exclusivamente a las asociaciones de consumidores y usuarios que, conforme a la Ley, fuesen consideradas representativas, es decir, aquellas integradas en el Consejo de Consumidores y Usuarios (art. 11.3) ${ }^{55}$.

En los dos supuestos anteriores, el control que despliega el juzgador sobre la legitimación del demandante es de carácter esencialmente formal. Únicamente para el ejercicio de las acciones de cesación, al criterio formal de encontrarse incluida la entidad en el listado que, a tal fin, se publica en el Diario Oficial de la Unión Europea, se añade la posibilidad del juez de examinar si la finalidad de la entidad y los intereses afectados "legitiman el ejercicio de la acción" (art. 11.4 II LECiv). Esta especial atribución al juez, que le permite considerar, desde una perspectiva casuística si, atendiendo al objeto del proceso y a los fines declarados de la entidad demandante,

\footnotetext{
${ }^{54}$ Sobre los presupuestos de las class actions norteamericanas, véase LópEZ (2011), pp. 19-28, donde hace alusión a los requisitos de numerosity (que la clase sea suficientemente numerosa), commonality (existencia de cuestiones de hecho o de derecho comunes a la clase), así como a la tipicality (correspondencia entre las pretensiones y defensas del representante y de la clase) y a la representativeness (adecuación del representante para proteger los intereses de la clase), explicando el control que despliega el juez a la hora de valorar su concurrencia y de decidir, por lo tanto, si el asunto puede tramitarse como una acción de clase.

55 Según el art. 24.2 del Real Decreto Legislativo $N^{\circ}$ 1/2007, de 16 de noviembre, por el que se aprueba el texto refundido de la Ley General para la Defensa de los Consumidores y Usuarios y otras leyes complementarias, "tendrán la consideración legal de asociaciones de consumidores y usuarios representativas las que formen parte del Consejo de Consumidores y Usuarios, salvo que el ámbito territorial del conflicto afecte fundamentalmente a una comunidad autónoma, en cuyo caso se estará a su legislación específica".
} 
esta se encuentra legitimada para ejercer la acción, es loable, aunque de ámbito absolutamente insuficiente. Piénsese que esta atribución judicial sólo se permite en las acciones de cesación, quedando vedada en el resto de acciones colectivas, y además cierra al juzgador la posibilidad de valorar otros criterios, que podrían ser mucho más relevantes que los fines recogidos en el estatuto de la entidad demandante, tales como su experiencia en el ejercicio de acciones colectivas, los recursos económicos con que cuente para conducir adecuadamente el proceso o sus antecedentes, ya en sede judicial, ya extrajudiciales, en la defensa de intereses análogos a los que sean objeto del proceso en cuestión.

Cuando, como ocurre en España, se atribuye legitimación a determinadas entidades públicas o asociaciones privadas, exigiéndoles estar inscritas en un determinado registro o tener un concreto fin social, el control de legitimación se realiza a nivel legislativo y/o administrativo, por lo tanto, de forma abstracta y desvinculada del caso concreto. En este sentido, tal y como manifiesta Pellegrini Grinover, cabe señalar que el sistema de legitimación ope legis, frente a aquel otro en que la adecuada representatividad es valorada ope iudicis, presenta problemas prácticos por la conducción de acciones colectivas por parte de asociaciones que, aunque cumplen con los requisitos legales, no demuestran la credibilidad, la seriedad, el conocimiento técnico científico o la capacidad económica para llevar a cabo una defensa procesal eficaz ${ }^{56}$.

Si se compara la regulación española con la del Código Modelo, lo primero que se observa es que la legitimación en este último es mucho más amplia, ya que incluye entidades públicas y privadas, organismos públicos, partidos políticos y sindicatos, así como a los particulares ${ }^{57}$. Pues bien, quizás por coherencia con la opción de dar entrada a los particulares, o quizás por ser consciente de la relevancia social de los bienes que están en juego en estos procesos, el Código Modelo otorga al juez amplias facultades de control para valorar la representatividad del demandante, siendo uno de los requisitos para admitir la demanda colectiva, la adecuada representatividad del mismo (art. $\left.2^{\circ} \mathrm{I}\right)$.

La exigencia de adecuada representatividad se hace depender, entre otros extremos, de su credibilidad, capacidad, prestigio y experiencia, de

\footnotetext{
${ }^{56}$ Pellegrini (2002), p. 14.

57 La mayor amplitud de la legitimación se explica porque el Código Modelo sirve para la tutela de todo tipo de intereses de grupo, mientras que la LECiv se limita, casi exclusivamente, a los de consumidores y usuarios. Esta excesiva limitación del ámbito de la LECiv resulta criticable, en tanto que deja fuera $y$, por lo tanto, sin posibilidad de tutela colectiva, multitud de derechos e intereses dignos de protección.
} 
sus antecedentes en la defensa de los intereses en liza en sede judicial y extrajudicial, de su conducta en anteriores procesos colectivos, de la coincidencia de sus intereses con los del grupo o clase, así como, en su caso, del tiempo que lleva constituida como tal la entidad demandante y, en fin, de su representatividad respecto del grupo (cfr. art. $2^{\circ}$ párr. $2^{\circ}$ ). Este listado, que no se configura como numerus clausus, incluye factores tan amplios y dispares que, claramente, hace recaer el peso principal de la valoración en el juez, al que se otorga, en concordancia con la transindividualidad y relevancia de los intereses en liza, amplios poderes de decisión.

Además, el Código dispone que el juez podrá analizar la representatividad del legitimado en cualquier tiempo y grado del procedimiento, sin necesidad de petición de parte (art. $2^{\circ}$ párr. $3^{\circ}$ ). Se rompe así con el principio de perpetuatio legitimationis, optándose por favorecer una representatividad real, verificada por el juez a lo largo del proceso, frente a una legitimación meramente formal, verificada, puntualmente, en el momento de admisión de la demanda.

Por el contrario, en España, sigue rigiendo la regla general de perpetuación de la legitimación, como un efecto más de la litispendencia, que se produce desde la interposición de la demanda, una vez que esta es admitida (art. 410 LECiv), sin que el juez pueda controlar la adecuada representatividad del demandante en el curso del proceso. Las facultades del juez, también en este punto, son excesivamente limitadas.

En definitiva, en el Código Modelo se observa que el juez ostenta el poder-deber de valorar casuísticamente si quien se erige en representante de la clase es el adecuado para hacer valer procesalmente sus intereses, estando especialmente atento a detectar y prevenir conflictos de intereses, fraudes o actuaciones perjudiciales para los miembros ausentes del grupo.

Pues bien, la referida solución legal del Código Modelo resulta adecuada en las acciones colectivas, toda vez que el demandante tiene la capacidad de vincular, con su actuación procesal, a terceros, que no son parte en el proceso y que, en ocasiones, ni siquiera han tenido un conocimiento efectivo de la pendencia del mismo. Por este motivo, la actuación de ese demandante puede y debe de ser controlada por el juez para impedir abusos y, en definitiva, para asegurar una adecuada defensa y representación de los intereses de todos los miembros de la clase, y particularmente de los ausentes, esto es, de aquellos que no están personados individualmente en el proceso ${ }^{58}$. En este sentido, cabe afirmar que la fuerza de cosa juzgada frente a terceros

${ }^{58}$ En la misma línea, Aguirrezabal (2010) p. 187, sostiene que "si la sentencia que se pronuncia en un procedimiento colectivo resulta obligatoria incluso para aquellos que no hayan tenido intervención 
presupone una adecuada representación en el proceso de los intereses de esos terceros, so pena de vulnerar su derecho de defensa y, por lo tanto, una de las garantías básicas del debido proceso legal ${ }^{59}$.

Ahora bien, evidentemente, tal y como apunta Bujosa Vadell, las limitaciones del principio dispositivo en las acciones colectivas, en ningún caso, pueden llegar a suponer la aplicación del principio de oficialidad, en el sentido de que sea el propio juez el que, de oficio, inicie el proceso ${ }^{60}$. Esto no es admisible, ni siquiera, en el proceso penal, regido por el principio de oficialidad, ya que, aunque en este proceso se permite, en ciertos casos, la iniciativa de oficio al juez instructor (arts. 303 y 308 LECrim), este vestigio del antiguo proceso penal inquisitivo, sólo se justifica si se considera que existe una clara y tajante separación entre el juez que instruye y el que juzga $^{61}$. Por lo tanto, la iniciación del proceso civil de oficio sería inadmisible, incluso en los procesos colectivos, dado que no existe, al menos en España, una previa fase de instrucción de la que conozca un juez distinto del que fallará el asunto.

Lo que sí resulta admisible, tal y como sostiene Guasp Delgado, tras reafirmar la vigencia general del principio nemo iudex sine actore, es que, cuando surge, en el proceso civil, un interés supraindividual, cuya satisfacción interesa al Estado, se vele por él, mediante la atribución de funciones de protección a un órgano oficial, distinto del juez que, en el ordenamiento jurídico español, vendría a ser, siempre según el citado autor, el Ministerio Fiscal ${ }^{62}$. Pues bien, esto es precisamente lo que ha venido a hacer la Ley $N^{\circ} 3 / 2014$, de 27 de marzo, al introducir un apartado $5^{\circ}$ en el art. 11 LECiv, que reconoce la

en el proceso, el legislador y el órgano jurisdiccional deben estar en condiciones de determinar quién es capaz de representar adecuadamente sus intereses en el tribunal".

${ }^{59}$ Como recoge López (2011), pp. 62-63, cierta doctrina entiende que, en Estados Unidos, si el miembro de la clase no personado en el proceso llega a demostrar que la representación fue inadecuada, podrá evitar el efecto vinculante de la decisión que le ponga fin.

${ }^{60}$ Bujosa (2015), p. 7

${ }^{61}$ A pesar de esta separación entre la fase de instrucción y enjuiciamiento NieVA (2012), p. 116, sostiene que la iniciación de oficio del proceso penal por el juez instructor presenta riesgos para la imparcialidad del juez y para el derecho al juez ordinario predeterminado por la ley, debiendo quedar su ámbito estrictamente limitado a aquellos casos en que el Juez recibe la notitia criminis, a través de un medio de comunicación o de un hallazgo casual, en el marco de otro procedimiento. Más ampliamente, sobre esta cuestión, destaca la obra del mismo autor Nieva (2001).

62 Guasp (1943), p. 33; en una línea similar Bujosa (2007), p. 609, señala que la indefinición entre intereses supraindividuales e intereses generales presenta la ventaja de permitir acumular mecanismos de distinta naturaleza para proteger tales intereses, combinando instrumentos públicos como el Ministerio Fiscal y el Defensor del Pueblo, con otros privados, como las organizaciones no gubernamentales. 
legitimación del Ministerio Fiscal para ejercitar cualquier acción en defensa de los intereses de los consumidores y usuarios ${ }^{63}$.

Por su parte, el Código Modelo contempla que, ante el desistimiento o la pérdida de legitimidad por parte del demandante, el juez pueda dirigirse al Ministerio Fiscal o a otros legitimados para que sostengan la acción (art. $3^{\circ}$ párr. $4^{\circ}$ ). Esto recuerda, salvando las distancias, a la búsqueda de acusadores particulares que realiza el juez de instrucción, cuando el Ministerio Fiscal solicita el sobreseimiento de la causa, pudiendo acordar, el juez instructor, que se haga saber la pretensión del Ministerio Fiscal a los directamente ofendidos o perjudicados conocidos, no personados, para que comparezcan a defender su acción si lo consideran oportuno o pudiendo acudir, en su caso, al superior jerárquico del Fiscal para que resuelva si procede o no sostener la acusación (art. 782.2 LECrim).

En contraste, en la LECiv nada se establece en relación con la posibilidad de que el juez proponga a otros legitimados sostener la acción, en caso de que el demandante inicial no se muestre diligente en su tarea de conducción del proceso. Esta situación resulta, si cabe, más preocupante si se considera que, en la regulación española, al contrario de lo que dispone el Código Modelo, según parece desprenderse de la letra de la LECiv, la cosa juzgada material de las acciones de grupo se extiende, en principio, a terceros, aun cuando la sentencia sea desestimatoria de las pretensiones del actor (art. $222.1 \mathrm{y}$ 3), por ejemplo, por falta de pruebas o por un planteamiento erróneo de la demanda.

\subsubsection{El control judicial sobre la admisibilidad de la demanda}

Otro momento clave de las acciones colectivas, en el que los poderes del juez deberían verse reforzados, es el de la decisión sobre la admisión de la demanda. Así pues, al analizar el Derecho extranjero, se observa que, normalmente, el juez goza de amplios poderes discrecionales a la hora de decidir sobre la admisibilidad de la demanda como forma de iniciar un proceso colectivo ${ }^{64}$.

\footnotetext{
${ }^{63}$ Igualmente, en Brasil, el art. 129.3 de la Constitución del año 1988, señala que, una de las funciones del Ministerio Público consiste en promover la demanda civil y la acción civil pública, para la protección del patrimonio público y social, del medio ambiente y otros intereses difusos y colectivos.

${ }^{64}$ En Estados Unidos existe la certificación de la clase, que constituye una resolución judicial que, tras verificar la concurrencia de una serie de presupuestos, permite tramitar una acción como colectiva. En este examen preliminar, el juez debe analizar si la acción planteada encaja en alguno de los tipos de acciones colectivas definidos en la Rule 23, de las Federal Rules of Civil Procedure, en concreto en la Rule 23 (b) y, además, si concurren los cuatro requisitos dispuestos en la Rule 23
} 
Concretamente, el art. 2 del Código Modelo señala como requisitos de la demanda colectiva la adecuada representatividad del legitimado, analizada en el epígrafe anterior, y la relevancia social de la tutela que se pide. Pues bien, para valorar estos extremos, el Código Modelo establece una serie de criterios que, irremediablemente, precisan de una actividad de valoración discrecional por parte del juzgador para ser dotados de contenido. Bien entendido esto, en el sentido, apuntado por Vázquez Sotelo, de que la libertad judicial ni es discrecionalidad o libre albedrío ni entraña en ningún caso desvinculación de los principios superiores del ordenamiento, sino que el Tribunal debe actuar siguiendo la prudentia iuris en función de las circunstancias y pruebas que concurran en el caso ${ }^{65}$.

Así pues, la relevancia social dependerá de la naturaleza del bien jurídico lesionado, de las características de la lesión o del elevado número de personas perjudicadas (art. $2^{\circ}$ II Código Modelo). No establece el Código cuál ha de ser concretamente esa naturaleza, más allá de que deba tratarse de intereses individuales homogéneos o supraindividuales, tampoco se indica qué características de la lesión han de observarse -gravedad, extensión de los efectos, urgencia de la cesación en la producción del daño o de la reparación, etc.-, ni se establecen referencias numéricas sobre lo que ha de considerarse un número elevado de perjudicados. Cabe afirmar, por lo tanto, que en aplicación de estas normas, las facultades valorativas y decisorias del juez, para admitir o inadmitir la demanda colectiva, son bastante amplias.

A mayor abundamiento, en el caso de que el litigio verse sobre intereses individuales homogéneos, se exige al juez valorar ad limine litis, en tanto que condición de admisibilidad, el predominio de las cuestiones comunes sobre las individuales, así como la utilidad de la tutela colectiva en el caso concreto (art. $2^{\circ}$ párr. $1^{\circ}$ Código Modelo). Así pues, los redactores del Código, conscientes de que en este caso, al referirse el proceso a derechos individuales, existe la alternativa de su tutela independiente por cada titular, atribuyen al juez el poder de determinar si la tutela colectiva, en el caso concreto, resulta idónea.

\footnotetext{
(a). El primero, que la clase sea lo suficientemente numerosa como para que no resulta manejable una acumulación subjetiva de pretensiones (numerosity). El segundo, que existan cuestiones de hecho o de derecho comunes a todos los miembros de la clase (commonality). En tercer lugar, que las pretensiones de tutela de los demandantes sean homogéneas con las de la clase (tipicality). Y, por último, que los sujetos demandantes se muestran como adecuados para defender los intereses de la clase (adequacy). Pone de manifiesto Carballo (2009), p. 90, que este sistema de certificación ha sido acogido por varios legisladores, tales como el argentino, el danés, el neerlandés, el finlandés y el noruego, entre otros.

${ }^{65}$ VÁzquez (1995), pp. 60-61.
} 
Nuevamente, la relevancia de los intereses en juego, su carácter transindividual y la ausencia en el proceso de todos los interesados justifica atribuir al juez mayor poder para controlar, no sólo el cumplimiento de los presupuestos procesales y la adecuación del demandante para lograr la tutela pretendida, sino también la conveniencia de tramitar la pretensión como colectiva. Frente a esto, de acuerdo con la LECiv, que nada establece al respecto en relación con los procesos colectivos, en España se aplicará el general principio dispositivo que, a estos efectos, y según la exposición de motivos de la norma, implica que no podrá gravarse al tribunal con el deber y la responsabilidad de decidir qué tutela, de entre todas las posibles, puede ser la que corresponde al caso, siendo el que la solicita el que tiene la carga de determinar con precisión lo que pide.

En este punto, de nuevo, se acusa, en el ordenamiento jurídico español, la falta de un auténtico sistema de tutela de los intereses de grupo. Tal y como se indicó ut supra, la LECiv sólo prevé que el juez ante el que se ejercita una acción colectiva desarrolle un control formal sobre la legitimación de la entidad demandante, limitándose a verificar que la misma se encuentra habilitada conforme a la ley para ejercer la acción, lo que se hace depender de cuestiones tales como la finalidad que venga declarada en sus estatutos o el hecho de que se encuentre inscrita en un determinado registro público o que forme parte de determinados organismos públicos, como el Consejo de Consumidores y Usuarios.

En definitiva, la ausencia de condiciones específicas para la admisión a trámite de las demandas colectivas, junto con la falta de atribuciones al juzgador para orientar a las partes en la determinación del tipo de tutela que conviene más a sus intereses, obliga a acudir a la regla general del proceso civil español, según la cual, las demandas sólo se inadmitirán por causas tasadas expresamente previstas en la ley (art. 403.1 LECiv). Consecuentemente, el juez tendrá que limitarse a realizar un control formal en la admisión de la demanda colectiva, lo que abre la puerta al ejercicio inadecuado, cuando no fraudulento, de estas acciones, con graves consecuencias, tanto para los intereses en juego como para los interesados no demandantes ${ }^{66}$.

Cabe añadir, en este punto que, para que el examen de admisibilidad no quede reducido a una mera verificación formal y sirva, en definitiva, para

\footnotetext{
${ }^{66}$ VÁzQuez (2007), p. 902. Aunque la legislación española faculta a los Juzgados y Tribunales para rechazar fundadamente las peticiones que se formulen con manifiesto abuso de derecho o entrañen fraude de ley o procesal (art. 11.2 Ley Orgánica № 5/1985, de 1 de julio, del Poder Judicial), este deber genérico no parece suficiente para permitirles desplegar un examen sobre la adecuación del representante o la idoneidad de la tutela colectiva para el caso concreto, sobre todo cuando, tal y como se ha indicado, la inadmisión de la demanda solo procede en supuestos tasados.
} 
garantizar la idoneidad del proceso colectivo como forma de tutela de los intereses en liza, puede ser necesario que el órgano judicial desarrolle una cierta actividad instructora, a fin de complementar la información contenida en la demanda, verificando que concurren los requisitos de admisibilidad, sin que, ante la insuficiencia de los datos aportados por el demandante, deba procederse directamente a la inadmisión ${ }^{67}$. En este sentido, el principio pro actione abogaría por permitir al juez requerir datos y complementar aquellas informaciones necesarias para decidir sobre la admisión o inadmisión de la demanda colectiva. Se evitaría, así, hacer recaer el peso del impulso procesal de modo exclusivo en el demandante, como ocurre en un proceso acentuadamente dispositivo ${ }^{68}$.

\subsubsection{El principio de aportación de parte y la iniciativa probatoria del juez}

En relación con las reglas que rigen la aportación de los hechos y la iniciativa probatoria, aparece el principio de aportación de parte, enfrentado al inquisitivo o de investigación de oficio. Según este principio "son las partes, y no el juez, las que tienen la responsabilidad de traer los hechos al proceso" ${ }^{\prime \prime}$ y, así mismo, las que deben de proponer las pruebas que consideren útiles y pertinentes para acreditarlos.

Tanto el principio de aportación de parte como el principio dispositivo responden, en definitiva, a la naturaleza del derecho material que, como norma general, se tutela a través del proceso civil, es decir, a la naturaleza propia del Derecho Civil, que se rige por el principio de la autonomía de la voluntad ${ }^{70}$. Sin embargo, los principios dispositivo y de aportación de parte, aun cuando tradicionalmente han sido vinculados por parte de la doctrina ${ }^{71}$, no deben de confundirse.

Pues bien, mientras que la disponibilidad del derecho material o de la pretensión se viene admitiendo sin ambages cuando se trata de derechos subjetivos privados, la limitación estricta de la iniciativa probatoria a las partes es una cuestión más discutible y, de hecho, ha sido una cuestión intensamente

67 Bujosa (2015), p. 24.

${ }^{68}$ Couture (1997), p. 187.

69 NieVA (2014), p. 171.

70 MOntero (2016), pp. 35-39.

71 Así pues, según VÁzquez (2009), pp. 38-43, del principio dispositivo se puede hablar en dos sentidos muy diversos. El autor recuerda la distinción introducida en el siglo XIX por los procesalistas alemanes entre la máxima dispositiva del propio derecho (Dispositionsmaxime) y el principio de la gestión en el proceso del propio derecho (Verhandlungsmaxime). 
discutida en la doctrina española, entre quienes abogan por excluir absolutamente cualquier facultad judicial al respecto ${ }^{72}$ y quienes sostienen que el juez no puede quedar sujeto a aquello que las partes alegan y prueban, sin posibilidad de desligarse de esa verdad formal que le presentan ${ }^{73}$.

En cualquier caso, lo que aquí interesa destacar es que también esta faceta del principio dispositivo, referida a los límites de la iniciativa probatoria, demanda matizaciones en los procesos colectivos. Así pues, el Código Modelo directamente implanta la iniciativa probatoria de oficio, siempre con el debido respeto al contradictorio (art. 12 párr. $3^{\circ}$ ), pudiendo, además, el juzgador, suplir las deficiencias de las partes en la aportación de pruebas, cuando estas, por razones técnicas o económicas, no pudieran cumplir con las cargas probatorias que les corresponden y previéndose, específicamente, la posibilidad de requerir pericias a entidades públicas cuyo objeto estuviere ligado a la materia en debate (art. 12 párr. $1^{\circ}$ ).

Frente a esto, la LECiv, que tampoco establece especialidad alguna para las acciones colectivas en materia probatoria, sigue partiendo de la regla general según la cual la iniciativa probatoria corresponde a las partes (art. 282), limitándose a regular una tímida intervención judicial en la audiencia previa. Esta posibilidad de intervención se limita a permitir al juez, que considera que las pruebas propuestas por las partes pudieran resultar insuficientes para el esclarecimiento de los hechos controvertidos, ponerlo de manifiesto, indicando el hecho o hechos que, a su juicio, podrían verse afectados por tal insuficiencia probatoria (art. 429.1.III LECiv).

Nótese que el citado precepto recoge una mera invitación a las partes, para que suplan la carencia probatoria detectada por el Tribunal, con una velada advertencia de que, en caso de no hacerlo, se aplicarán las reglas de la carga de la prueba, en perjuicio de la parte a quien le correspondería haber probado. Por otra parte, ocurre que, al preverse esta advertencia en la audiencia previa, pierde gran parte de su utilidad, en tanto que, en ese momento, el juez no puede conocer de antemano el resultado de la práctica de

\footnotetext{
72 Puede verse, en este sentido, la monografía de Montero (2001).

${ }^{73}$ En este sentido, VázQuez (2009), pp. 21-74, tras tachar la regulación contenida en la LECiv de "ultraliberal", reclama la recuperación de ciertas facultades judiciales en lo que a la iniciativa probatoria se refiere; por su parte, NIEVA (2014), pp. 173-175, señala que, si bien es cierto que la LECiv parte del principio de aportación de parte (art. 282), también contiene manifestaciones inquisitivas marginales (arts. 429.1 II y 435.2), así como preceptos que permitirían al juez advertir a las partes acerca de las dudas que puedan plantear sus peticiones o de lagunas detectadas en el relato de hechos aportado por aquellas (arts. 424 y 426.6). Para el autor, estas facultades de advertencia, previstas en la LECiv, aunque son escasamente utilizadas en la práctica por los jueces, son positivas, en tanto que hacen del proceso un mecanismo útil para la resolución auténtica y no fraudulenta de los conflictos.
} 
las pruebas para valorar qué hecho o hechos se verán afectados por la referida insuficiencia probatoria ${ }^{74}$.

Más allá de esta "facultad de advertencia", la LECiv sólo regula la iniciativa probatoria de oficio, con carácter excepcional y con un ámbito de aplicación extremadamente limitado, en las denominadas diligencias finales, a través de las cuales se permite al juez acordar la repetición de pruebas ya practicadas, en el específico supuesto de que "los actos de prueba anteriores no hubieran resultado conducentes a causa de circunstancias ya desaparecidas e independientes de la voluntad y diligencia de las partes, siempre que existan motivos fundados para creer que las nuevas actuaciones permitirán adquirir certeza sobre aquellos hechos" (art. 435.2). Parte de la doctrina critica, a mi juicio con razón, la sustitución de las antiguas diligencias para mejor proveer reguladas en el art. 340 LEC 1881, por estas restrictivísimas diligencias finales ${ }^{75}$, que, además, por si fuera poco, se regulan única y exclusivamente, para el procedimiento ordinario, y no en el ámbito del juicio verbal, con lo que, a los efectos que aquí interesan, no podrían acordarse, por ejemplo, en un proceso en el que se ejercitase una acción de cesación para la defensa de los intereses colectivos o difusos, supuesto en el que procedería seguir los trámites del juicio verbal (art. 250.12 ${ }^{\circ}$ LECiv).

Los mismos motivos, tantas veces referidos, en cuanto a la relevancia social de los intereses en liza y la afectación de terceros no intervinientes en el proceso, conducen a postular, al menos en los procesos colectivos, la recuperación de las diligencias para mejor proveer, así como también a otorgar al juez la posibilidad de acordar de oficio la práctica de ciertas pruebas que considere necesarias, tras la proposición probatoria de las partes en la propia audiencia previa.

Así pues, en mi opinión, la posibilidad de designar peritos de oficio, en el marco de un proceso colectivo, debería preverse con carácter general, para permitir al juzgador entender y valorar mejor cuestiones tales como la gravedad del daño o lesión, la relación de causalidad entre la actuación ilícita y el perjuicio causado, el montante de las indemnizaciones que correspondan a

\footnotetext{
${ }^{74}$ Esta misma crítica se encuentra en VÁzQuez (2009), p. 27, quien achaca el poco uso, en la práctica judicial, de esta posibilidad, precisamente, a la imposibilidad de determinar la existencia de una insuficiencia probatoria antes de la práctica de la prueba, advirtiendo además que la facultad de advertencia prevista en la LECiv podría comprometer la imparcialidad del juez ante las partes mucho más que acordar de oficio una prueba complementaria o suplementaria sobre algún hecho.

75 VÁzqueZ (2009), pp. 61-64; VÁzquez (2007), p. 931, específicamente en relación con los procesos colectivos, vuelve a censurar la eliminación de las diligencias para mejor proveer, que permitirían al juez acordar la práctica de cualquier medio de prueba que considerase necesario para conocer la realidad de ciertos hechos.
} 
los perjudicados u otros extremos complejos que requieran de conocimientos técnicos o especializados para su correcta apreciación ${ }^{76}$.

Sin embargo, la ley española nada dice sobre las posibilidades de acordar pruebas de oficio, disponiendo, por ejemplo, que, en los procesos colectivos relativos a actuaciones discriminatorias por razón de sexo, el órgano judicial, solo a instancia de parte, podrá recabar, informe o dictamen de los organismos públicos competentes y, además, según parece desprenderse de la redacción del precepto, exclusivamente a los efectos de que el demandado pueda probar la ausencia de discriminación en las medidas adoptadas (art. 217.5 LECiv).

Creo, además, que, en algunos casos, también podría ser admisible y conveniente que el juez pudiera, de oficio, acordar la práctica de la prueba de reconocimiento judicial, así como ordenar coactivamente la entrega de determinados documentos, ya en la audiencia previa, ya celebrada la vista oral o, incluso, advertir a las partes de la conveniencia de escuchar, en calidad de testigo, a alguno o algunos de los miembros del grupo no personados en la causa.

Por otra parte, en lo relativo a las reglas sobre carga de la prueba, en el sistema previsto en el Código Modelo, el juzgador decide, en cada caso, sobre la distribución de la iniciativa probatoria, en función de determinadas circunstancias relativas a la supuesta posesión de informaciones o conocimientos sobre los hechos por alguna de las partes, así como a la mayor facilidad de su demostración (art. $12^{\circ}$ párr. 1). Se dispone, así mismo, que ante cambios en las circunstancias, el juez pueda modificar su decisión inicial sobre la distribución de las cargas probatorias (art. 12 párr. $2^{\circ}$ ), lo que amplia todavía más sus, ya de por sí extensas, posibilidades de actuación en lo que a la actividad probatoria se refiere ${ }^{77}$.

Por lo tanto, el Código Modelo instaura un sistema de carga probatoria dinámica ${ }^{78}$, acorde con los mayores poderes decisorios que debe ostentar el juez en estos procesos, así como con la complejidad y el dinamismo propios de las acciones colectivas, que demandan huir de las rigideces derivadas de

\footnotetext{
${ }^{76}$ La LECiv admite la designación de oficio de un perito para que dictamine sobre la efectiva producción de los daños y su evaluación en dinero, cuando el deudor, en fase de ejecución, se opone a la liquidación de daños y perjuicios (art. 715), seguramente por la complejidad de la materia. Pues bien, este criterio, aun con mayor fundamento, abogaría por extender tal regla, por ejemplo, a un proceso colectivo en el que fuese necesario determinar los daños producidos en la salud de un grupo de personas indeterminado, por haber consumido un alimento tóxico. La mayor amplitud subjetiva del conflicto, como norma general, implicará una mayor complejidad.

77 Bujosa (2015), pp. 17-21.

78 Sobre esta cuestión, véase PeYrano y Lépori (2008).
} 
una distribución estática de la carga probatoria. Además, a esto hay que añadir el hecho de que en los procesos colectivos previstos en el Código Modelo, cuando la pretensión fuere rechazada por insuficiencia de pruebas, cualquier legitimado podrá intentar otra acción, con idéntico fundamento, si se valiere de nueva prueba (art. $33^{\circ}$ ). De esta forma, se flexibiliza el efecto de la cosa juzgada, al que se hará referencia más detenida en el epígrafe siguiente.

La LECiv, por su parte, en su exposición de motivos, tras alabar las bondades de las normas sobre carga probatoria para acertar en el enjuiciamiento, indica que la iniciativa probatoria de parte es el principio general vigente, sin perjuicio de que, en los casos en que esté implicado un interés público, resulte exigible que se agoten, de oficio, las posibilidades de esclarecer los hechos. Atendiendo a esta enunciación, podría pensarse que la regulación contiene en su articulado normas específicas sobre carga de la prueba para los procesos colectivos en los que, como tantas veces se ha indicado, los derechos en liza se encuentran a medio camino entre los públicos y los privados. Sin embargo, lo cierto es que la LECiv apenas contiene especialidades en este sentido.

Sólo para los procesos sobre competencia desleal y publicidad ilícita, así como en aquellos en los que las alegaciones de la parte actora se fundamenten en actuaciones discriminatorias por razón del sexo, se produce una suerte de inversión de la carga probatoria, señalando que será el demandado el encargado de probar la exactitud y veracidad de las indicaciones y manifestaciones realizadas, de los datos materiales que la publicidad exprese o, en su caso, de acreditar la ausencia de discriminación o la proporcionalidad de las medidas que se señalan como discriminatorias en la demanda colectiva (arts. 217. 3 y 4 LECiv).

Para el resto de procesos colectivos, se aplican las normas generales sobre carga de la prueba, según las cuales corresponde al demandante probar los hechos constitutivos de su pretensión y al demandado los impeditivos, extintivos y excluyentes (arts. 217.2 y 3 LECiv). La rigidez de estas normas trata de flexibilizarse señalando que el tribunal deberá tener presente la disponibilidad y facilidad probatoria que corresponde a cada una de las partes del litigio (art. 217.7 LECiv), sin que, en principio, esta última regla pueda servir para invertir sistemáticamente la distribución de la carga de la prueba, sino más bien como criterio interpretativo del juzgador a la hora de dictar sentencia.

Las rigideces de las reglas sobre carga de la prueba, junto con las limitadas iniciativas probatorias que se reconocen al juez civil español, pueden provocar que la demanda colectiva sea desestimada, por no haber logrado el demandante acreditar los hechos que fundamentan su pretensión, lo que 
podría implicar un injusto perjuicio para los intereses supraindividuales en liza, así como para los titulares de los derechos individuales homogéneos, a los que solo les quedaría la posibilidad, en su caso, de litigar individualmente.

Pues bien, considero que no es justo dejar toda la carga de acreditación de los hechos afirmados en la demanda colectiva, exclusivamente, en manos del demandante, ni derivar de su incapacidad para probar los hechos que alega, consecuencias tan graves para los derechos e intereses en litigio de los que, cabe recordar, el demandante no es titular exclusivo. Así pues, en definitiva, debemos de convenir con Bujosa Vadell que, si la materia del juicio trasciende el interés de las partes, está justificado el fortalecimiento de la posición del juez en la actividad probatoria ${ }^{79}$.

Ahora bien, las facultades judiciales que prevé el Código Modelo en relación con la prueba, y cuya adopción se propugna para la regulación de un futuro proceso colectivo en España, han de respetar ciertos límites. En primer lugar, es necesario que la distribución de la carga de la prueba que, en su caso determine el juzgador, se funde en indicios razonables y objetivos para determinar la facilidad probatoria o los conocimientos que se le presumen a cada parte. En segundo lugar, hay que observar el principio estructural de igualdad de armas, de tal forma que la intervención judicial no incline la balanza en favor de una parte, dándole más oportunidades de alegar y probar que a la contraria. En tercer lugar, como exigencia del proceso con todas las garantías, es necesario que cualquier elemento de convicción, incluso los derivados de actuaciones que la ley permita al juez ordenar de oficio, sea sometido al tamiz de la contradicción, respetando escrupulosamente el derecho de defensa del demandado ${ }^{80}$. Y, por supuesto, hay que preservar la imparcialidad del juzgador, que no puede actuar como investigador introduciendo nuevos hechos en el proceso, ni como parte siquiera para defender la posición considerada débili ${ }^{81}$.

\subsubsection{La delimitación del thema decidendi y el ámbito de la cosa juzgada}

Una de las consecuencias directas del principio dispositivo consiste en que son las partes las encargadas de delimitar el objeto del proceso, tanto en

\footnotetext{
79 BuJOSA (2015), p. 12.

80 Zufelato (2017), p. 25.

${ }^{81}$ VÁzquez (2001), p. 116, señala que los poderes que se reconocen al juez en la dirección del proceso y en la aportación de pruebas deben establecerse de forma que no menoscaben, riesgo que se produce si el juez tiene que descender de su pedestal y ocupar la posición de parte.
} 
su vertiente objetiva como en su vertiente subjetiva ${ }^{82}$. Este principio, junto con el de preclusión, implica que, como regla general, el objeto del proceso queda determinado en la demanda y, además, que el juez no puede pronunciarse sobre cuestiones no planteadas por las partes, ni sobre sujetos distintos a aquellos identificados como demandantes y demandados.

Si se parte de un proceso civil dispositivo, que encierra un conflicto intersubjetivo, en el que las partes son absolutamente dueñas de los derechos en liza, es lógico que sean esas mismas partes las que fijen los términos de la contienda procesal. Pero es que, una vez más, cabe recordar, aun a riesgo de resultar reiterativa, que los procesos colectivos no encajan en tal esquema, que identifica al demandante con el titular de los derechos litigiosos, y por eso, también en la determinación del objeto procesal, se debe dar entrada, en ocasiones, al juzgador.

Así, por ejemplo, el Código Modelo prevé la posibilidad de que el juez pueda separar las pretensiones del demandante en procesos colectivos distintos, siempre que la separación represente economía procesal o facilite la conducción del proceso (art. 11. párr. $5^{\circ}$ II). Con esta desconexión, acordada por el órgano judicial, se afecta, de forma directa, a la determinación del objeto procesal, en pro de mejorar la manejabilidad del litigio ${ }^{83}$.

Por el contrario, según la legislación procesal civil española, el juzgador, en virtud del principio de congruencia (art. 218.1 LECiv), viene obligado a pronunciarse sobre todo lo que se le plantee. Y, concretamente, en relación con las acciones del grupo, se dispone que si, tras el Ilamamiento dirigido a los miembros del grupo, se personan consumidores o usuarios determinados, la sentencia habrá de pronunciarse expresamente sobre sus pretensiones (art. 221.1. $3^{\circ}$ LECiv).

Esta posibilidad de acumulación de acciones individuales a la acción colectiva puede poner en riesgo la efectividad de la tutela colectiva, ya que una acumulación sin control podría llegar a complicar excesivamente la tramitación del proceso, hasta convertirlo en inmanejable, sin que el juzgador, atendiendo a la regulación legal vigente, pueda hacer nada para remediarlo,

\footnotetext{
82 En este sentido, tal y como indica MOnTero (2016), p. 37, el principio dispositivo implica que la determinación concreta del interés cuya satisfacción se solicita a los tribunales es facultad exclusiva de los particulares, lo cual repercute en el objeto del proceso, que ha de ser determinado exclusivamente por el demandante a través de su pretensión.

83 Igualmente, en Estados Unidos, a través de la certificación por la que se admite a trámite la acción de clase, el tribunal decide el tipo de class action, lo que determina el procedimiento a seguir y los efectos de la resolución que llegue a dictarse, además define la clase y las pretensiones e, incluso, puede crear subclases [Rule 23 (c) (1). Federal Rules of Civil Procedure], determinando absolutamente el objeto del proceso, tanto desde el punto de vista subjetivo como objetivo.
} 
siempre que se cumplan los requisitos legales para la acumulación de acciones, consistentes en que entre las acciones exista un nexo por razón del título o causa de pedir, que sean competencia del mismo órgano y que deban tramitarse por el mismo tipo de procedimiento (arts. 72 y 73 LECiv).

Seguramente, para impedir una acumulación excesiva o inconveniente, que dé lugar a una "macrocausa" de difícil o imposible tramitación, el Código Modelo, además de permitir al juez desacumular acciones inicialmente acumuladas por el demandante, establece expresamente que quienes intervengan en el proceso colectivo, como asistentes o coadyuvantes, no podrán discutir en el mismo sus pretensiones individuales (art. $21^{\circ}$ párr. $3^{\circ}$ ).

Por otra parte, desde el punto de vista subjetivo, el principio dispositivo implica que la resolución que ponga fin al proceso sólo podrá referirse a quienes hayan sido parte en el mismo, en tanto que, como regla general, solo el titular del derecho que decide litigar, puede quedar vinculado por la resolución judicial que llegue a dictarse. Pues bien, en el caso de un proceso colectivo, esto no ocurre así, en tanto que la resolución que le pone fin, como se ha dicho en varias ocasiones, no siempre limita sus efectos a las partes procesales, desplegando, frecuentemente, efectos erga omnes o ultra partes ${ }^{84}$.

En España, la LECiv prevé que, cuando se pretenda la declaración de ilicitud de una conducta -piénsese, por ejemplo, en un caso en el que se pretenda el cese en la utilización de una cláusula contractual considerada nula por resultar abusiva-, el Tribunal determinará en la sentencia si tal declaración de ilicitud ha de surtir efectos procesales no limitados a quienes hayan sido partes en el proceso correspondiente o, por el contrario, si los efectos han de limitarse a quienes fueron parte en el concreto proceso (art. 221.1. $\left.2^{\circ}\right)^{85}$. Ahora bien, más allá de esta particular previsión, en relación con la extensión a terceros de los efectos de ciertas sentencias dictadas en un proceso colectivo, la LECiv no atribuye al juzgador facultades para acotar el objeto del proceso, a fin de centrarlo en las cuestiones comunes al grupo, ni para separarlo en distintos procesos de pretensiones homogéneas.

Adicionalmente, se observa que el amplio ámbito objetivo de la cosa juzgada previsto en la LECiv, abarcando no sólo lo efectivamente deducido

${ }^{84}$ Tal y como afirma PALOMO (2003), p. 199, el carácter erga omnes de la cosa juzgada es precisamente lo que da sentido a esta nueva forma de tutela jurisdiccional, por lo que resulta imprescindible cambiar la concepción individualista de la cosa juzgada.

${ }^{85}$ Según lo dispuesto en la Exposición de Motivos de la LECiv, con este precepto se evita una norma generalizadora que no podría abarcar la diversidad de casos de protección que podrían plantearse, dejando al tribunal la facultad de determinar la eficacia subjetiva, según su contenido y conforme a la tutela otorgada por la vigente ley sustantiva protectora de los derechos e intereses en juego. 
en juicio, sino también aquello que pudo deducirse (art. 400.2 LECiv), unido a la prohibición de mutatio libelli, que impide, como regla general, alterar el objeto del proceso determinado en la demanda (art. 412 LECiv) y a la fuerza con que, generalmente, actúa el principio de preclusión en el proceso civil español (art. 136 LECiv), del cual no se excepcionan los procesos colecti$\operatorname{vos}^{86}$, podría provocar que un planteamiento erróneo o insuficientemente fundamentado del conflicto, acabase con una sentencia desestimatoria, que impediría volver a plantear el litigio, con el consiguiente perjuicio para los intereses en juego y para todos los miembros del grupo, incluidos los ausentes.

Así pues, ocurre que el pronunciamiento del juez resolviendo la demanda colectiva despliega un efecto preclusivo, característico de la vertiente negativa de la cosa juzgada material, que impide el planteamiento de un ulterior proceso colectivo ${ }^{87}$, no solo cuando el segundo proceso se basa en los mismos hechos (art. 222.1 LECiv), sino también cuando se apoya en otros hechos o fundamentos, si estos pudieron ser alegados en el primero (art. 400.2 LECiv). Frente a esta indeseable situación, la doctrina propone que la cosa juzgada de las acciones colectivas se limite, únicamente, a aquellos hechos y fundamentos efectivamente deducidos en juicio y no a aquellos que pudieron deducirse ${ }^{88}$.

Tanto el art. 400 LECiv como el principio general de preclusión persiguen que el demandante no reserve posibles fundamentaciones de su pretensión para futuros momentos procesales o para ulteriores procesos. A tal fin, le impone la carga, siempre desde la perspectiva individualista característica de la LECiv, de esgrimir todos sus argumentos en la primera oportunidad,

\footnotetext{
${ }^{86}$ Este principio, sin embargo, sí se excepciona expresamente en otros procesos especiales, como los de familia, donde se asume sin traumas que, a pesar de tratarse de procesos civiles, se rigen normas imperativas o de ius cogens, en cuya aplicación, por lo tanto, no se aplica el principio dispositivo. En este sentido, según el art. 752.1 LECiv, los procesos especiales sobre capacidad, filiación, matrimonio y menores, "se decidirán con arreglo a los hechos que hayan sido objeto de debate y resulten probados, con independencia del momento en que hubieren sido alegados o introducidos de otra manera en el procedimiento".

${ }^{87}$ En este sentido, resulta interesante la última sentencia de la justicia española, dictada en el conocido caso de las cláusulas suelo de los contratos hipotecarios, en el que han sido consideradas nulas ciertas cláusulas contractuales que establecían un suelo o tipo mínimo para los deudores hipotecantes, que a pesar de las bajadas del tipo de referencia, tenían que seguir pagando el tipo de interés suelo, convirtiendo en la práctica en fijo un interés teóricamente variable. Así pues, la STS 123/2017, de 24 de febrero de 2017, F. J. $3^{\circ}$ indica que, entre acciones y colectivas y acciones individuales no existe identidad objetiva, puesto que tienen objetos y efectos jurídicos diferentes, con lo que no cabe apreciar los efectos de la cosa juzgada material. Consecuentemente, el efecto preclusivo de la cosa juzgada sólo puede afirmarse entre acciones colectivas, pero no entre acciones colectivas e individuales.
}

${ }^{88}$ Carballo (2009), pp. 237-239. 
"castigando" su falta de diligencia con la pérdida de la oportunidad de hacerlo posteriormente. Pues bien, este automatismo en la pérdida de oportunidades procesales no encaja con un sistema de acciones colectivas, en donde el litigante no va a ser el único, ni aun el principalmente afectado, por el resultado del proceso. Es por eso que el Código Modelo, tal y como se indicó ut supra, opta por un sistema de cosa juzgada secundum eventum litis para los procesos sobre derechos individuales homogéneos (art. $33^{\circ}$ párr. $2^{\circ}$ ) y secundum eventum probationem para los procesos sobre intereses supraindividuales (art. 21).

Igualmente, se propugna la flexibilización de la regla de mutatio libelli para los procesos colectivos, de tal forma que se puedan alcanzar resoluciones más justas y que desplieguen un mayor efecto pacificador. Y también, en este punto, el Código Modelo puede servir al legislador español de inspiración. Así pues, en el mismo se observa que el principio de mutatio libelli no encuentra aplicación en las acciones colectivas. En este sentido, el art. $10^{\circ}$ dispone que "el pedido y la causa de pedir serán interpretados extensivamente", que "el juez permitirá la enmienda de la demanda inicial para alterar o ampliar su objeto o la causa de pedir" y, así mismo, que se "permitirá la alteración del objeto de proceso en cualquier tiempo y en cualquier grado de jurisdicción, siempre que sea realizada de buena fe, no represente perjuicio injustificado para la parte contraria y el contradictorio sea preservado".

\subsubsection{La terminación anormal del proceso}

Por último, las matizaciones que viene Ilamado a experimentar el principio dispositivo en las acciones colectivas también se van a reflejar en las posibilidades de terminación anormal del proceso, ya a través de la firma de acuerdos, ya a través de otros actos dispositivos, tales como la renuncia, el allanamiento o el desistimiento.

Como es bien sabido, en un proceso informado por el principio dispositivo, las partes son enteramente dueñas tanto de trasladar su conflicto al proceso como de provocar, dentro de él, su finalización anormal, esto es, su terminación previa al dictado de la sentencia judicial ${ }^{89}$. Esto ocurre así, en tanto en cuanto, el proceso encierra un conflicto intersubjetivo, cuya titularidad corresponde exclusivamente a las partes ${ }^{90}$.

Sin embargo, en los procesos colectivos, la dimensión social de los intereses en juego, vinculada a la intrínseca indisponibilidad de los derechos

89 Gimeno (2010), p. 3-3.

90 Gimeno (2010), p. 3-3. 
supraindividuales o no susceptibles de apropiación individual, así como a la falta de coincidencia plena entre quien litiga y quien es titular del derecho cuando de intereses pluriindividuales se trata, justifica que las posibilidades de las partes para poner fin al proceso libremente, sin que se haya producido un auténtico juicio jurisdiccional, se vean limitadas.

De hecho, si se acude al Derecho comparado, se observa que, en los supuestos en que las normas reguladoras de las acciones colectivas prevén alguna posibilidad de terminación anormal del proceso, existe una generalizada preocupación porque los actos de disposición sean debidamente controlados por el juez ${ }^{91}$. Así ocurre, por ejemplo, en la regulación de las class action estadounidenses o en el sistema de acciones colectivas previsto en el ordenamiento jurídico brasileño o en el de los Países Bajos, entre otros.

Con respecto a la situación en España, la falta de sistema y de sistemática en lo que a la regulación de las acciones colectivas se refiere, se manifiesta, en este punto, en una absoluta falta de regulación. Así pues, la LECiv no prevé nada sobre las posibilidades que las partes del proceso colectivo tienen de renunciar, allanarse, desistir o transigir.

Ante esta laguna legal existen dos opciones. La primera pasaría por entender que a los procesos colectivos se aplican las normas de los procesos especiales sobre capacidad, filiación, matrimonio y menores, cuyo objeto se considera indisponible, y en los que, expresamente, se priva de efectos a los actos de renuncia, allanamiento o transacción (art. 751.1 LECiv). Por otra parte, la segunda posibilidad consistiría en realizar un esfuerzo hermenéutico para, aplicando las normas generales de la LECiv en esta materia, Ilegar a soluciones razonables, adaptadas a las especificidades de la tutela colectiva.

Pues bien, partiendo de la potencialidad que las soluciones negociadas o los actos de disposición podrían tener en el marco de la tutela colectiva, he decidido optar por la segunda de las dos alternativas referidas. Por eso, a continuación, se analizarán individualmente los distintos actos de disposición que las partes podrían realizar para poner fin anticipadamente al proceso colectivo.

Así pues, en primer lugar, estaría la renuncia, que se proyecta sobre el derecho subjetivo material que fundamenta la pretensión y sobre la pretensión misma, provocando la finalización anormal del proceso, mediante la emisión de una resolución jurisdiccional con todos los efectos de la cosa juzgada, que impide, por lo tanto, la incoación de un nuevo proceso sobre el mismo objeto de la renuncia ${ }^{92}$.

91 BuJOSA (2015), p. 11.

92 Gimeno (2010), pp. 3-16; sobre la polémica en torno a cuál es el verdadero objeto de la renuncia, véase Pérez-Cruz y Seoane (2011), pp. 409-410. 
La renuncia sólo es admisible cuando proviene del titular del derecho objeto de la misma, por eso el juez sólo debe aceptarla cuando se trata de un conflicto intersubjetivo, debiendo, por el contrario, rechazarla, por resultar "legalmente inadmisible" (art. 20.1 LECiv), cuando se encuentre comprometido el orden público o se perjudiquen, con este acto, intereses de terceros (art. 6. $2^{\circ}$ Código Civil).

Así pues, tratándose de intereses supraindividuales no cabría renuncia, por ser estos bienes de naturaleza indisponible, mientras que en el caso de los derechos individuales homogéneos tampoco sería válida la renuncia realizada por el legitimado para interponer la acción colectiva, sino que tendrían que ser cada uno de los titulares, individualmente, los que renunciasen a su derecho, de forma expresa y personal, tal y como viene exigiendo, generalmente, la jurisprudencia española para una renuncia válida ${ }^{93}$.

En cuanto al desistimiento, ya no está tan claro si sería admisible o no en los procesos colectivos. En sentido afirmativo, se pronuncia Carballo Piñeiro ${ }^{94}$, trayendo a colación el art. 2.3 Real Decreto $N^{\circ}$ 1.828/1999, de 3 de diciembre de 1999, por el que se aprueba el Registro de Condiciones Generales de la Contratación. Según este precepto, las anotaciones preventivas practicadas en el ejercicio de una acción colectiva de cesación, retractación o declarativa de condiciones generales, se cancelarán, a instancia de parte interesada, cuando la acción no hubiera prosperado por desistimiento.

Hay que considerar que, en este caso, al contrario de lo que ocurre con la renuncia, el desistimiento sólo implica dejación del ejercicio de la pretensión y, por lo tanto, del procedimiento, sin que dicha dejación suponga una disposición del derecho subjetivo material que permanece intacto ${ }^{95}$. Por consiguiente, el desistimiento carece de fuerza de cosa juzgada material, con lo que no se impide el ejercicio de otra acción colectiva o de las correspondientes acciones individuales en un ulterior proceso (cfr. art. 20.3.II LECiv).

Como consecuencia de dejar imprejuzgada la cuestión de fondo, el desistimiento puede resultar interesante para el demandante que, debido a la insuficiencia de pruebas o a las deficiencias en el planteamiento del pleito, se arriesga a ver desestimada su pretensión ${ }^{96}$. Esta posibilidad, por lo tanto, no se debería vedar al demandante de una acción colectiva, cuando encontrase

\footnotetext{
${ }^{93}$ El hecho de que la renuncia sea expresa y personal, viene siendo exigido por la jurisprudencia del Tribunal Supremo español de forma reiterada (ver, por todas, STS 686/2003, de 30 de junio).

94 Carballo (2009), p. 213.

95 Gimeno (2010), pp. 3-17.

${ }^{96}$ Gimeno (2010), pp. 3-18.
} 
óbices al éxito de su pretensión, por ejemplo, por carecer de elementos de prueba suficientes, ya que, en otro caso, se le obligaría a continuar con un proceso que, previsiblemente terminaría con una sentencia desestimatoria, con las consecuencias negativas, ya referidas, que tal situación podría acarrear en el marco de la actual regulación española, impidiéndose volver a plantear ulteriormente la misma acción, incluso basada en fundamentos diversos. Ahora bien, para dotarlo de mayores garantías, podría resultar conveniente que el desistimiento en los procesos colectivos tuviera que ser autorizado por el Ministerio Fiscal, como ocurre, en los procesos sobre capacidad, filiación, matrimonio y menores, por ser su objeto considerado indisponible (art. 751.2 LECiv).

A través del desistimiento, el demandante consigue dejar imprejuzgado el asunto, que podría volver a plantearse en el futuro, cuando el mismo u otro legitimado para interponer la acción tuviesen una posición negociadora más fuerte o contasen con pruebas más concluyentes. Esto debería tomarse en consideración por el juez cuando, en caso de oposición del demandado al desistimiento, tuviera que pronunciarse sobre su procedencia, debiendo ponderar, en tal supuesto, todos los intereses en juego, incluidos los de los miembros del grupo no personados en el proceso (art. 20.3.III LECiv).

Por su parte, el Código Modelo trata de prevenir desistimientos infundados, encargando al juez la búsqueda de nuevos legitimados dispuestos a sostener la pretensión en el procedimiento iniciado (art. $3^{\circ}$ párr. $\left.4^{\circ}\right)^{97}$. Por esta vía, el juez, haciendo un Ilamamiento dirigido al resto de legitimados para actuar en el proceso colectivo, podría forzar su continuación y su terminación "normal", esto es, a través de sentencia.

El contraste que, nuevamente, se observa entre la LECiv y el Código Modelo resulta coherente con el hecho de que, en la regulación española, los defectos en la fundamentación de la demanda o la insuficiencia probatoria puedan conducir a una sentencia desestimatoria perjudicial para los intereses de terceros, caso en el cual, el desistimiento serviría para evitar un mal mayor,

\footnotetext{
${ }^{97}$ En una línea similar, en Portugal, el art. 16.3 de la Ley № 83/95, reguladora del derecho de participación procedimental y de acción popular, establece que el Ministerio Fiscal puede sustituir al demandante en caso de desistimiento, al igual que en casos de transacción o conducta lesiva para los intereses en juicio. Según GASCón (2010), p. 82, el Ministerio Fiscal ejerce, por esta vía, un control sobre el contenido de las transacciones, incluso, Ilegando, en su caso, a forzar su rechazo y la continuación del proceso; Igualmente, en Estados Unidos, las exigencias establecidas para la aprobación de una transacción, se exigen para permitir un desistimiento por parte del demandante (Rule 23 (e). Federal Rules of Civil Procedure). Así se consigue evitar acuerdos entre el demandante y el demandado, que excluyan a la clase, y se materialicen en el proceso colectivo en un desistimiento formal, que, en la práctica, deja irresuelto el litigio para los ausentes, a cambio de un trato de favor para el demandante o para sus abogados.
} 
con consecuencias indeseables e injustas para la tutela de los derechos del grupo de afectados. Por el contrario, en el Código Modelo, el control que, de los presupuestos de admisibilidad de la demanda, realiza el juez y la falta de vigencia de la prohibición de mutatio libelli, que impide modificaciones en la demanda, junto con el régimen de cosa juzgada secundum eventum litis o secundum eventum probationem, justifica impedir el libre desistimiento por parte del demandante, buscando nuevos legitimados que sean Ilamados a hacer valer el interés transindividual en litigio.

En cuanto al allanamiento, que implica la disponibilidad por el demandado del derecho subjetivo o interés material que se discute en el proceso, la LECiv señala que no puede contravenir el ordenamiento jurídico (art. 19.1), por lo que, si se realiza en fraude de ley o supone renuncia al interés general o perjuicio de terceros, se rechazará (art. 21.1 LECiv). El Código Modelo no dice nada sobre este acto de disposición, que proviene del demandado, a pesar de que, a diferencia del ordenamiento jurídico español, prevé acciones de clase pasivas, esto es, ejercitadas contra un grupo, categoría o clase. Con lo que podría plantearse si el allanamiento del demandado se extendería a todos los miembros del grupo.

En cualquier caso, en relación con el allanamiento, simplemente interesa señalar que, conforme a la jurisprudencia reiterada del Tribunal Supremo español en la materia ${ }^{98}$, cuando existen varios litisconsortes, el allanamiento de uno no puede afectar al resto. Por eso, si se ejercita una acción de cesación, por ejemplo, para evitar que una determinada empresa continúe utilizando una específica cláusula en sus contratos, y la entidad se allana, no será posible oponer esa sentencia estimatoria a otras entidades que empleen en sus contratos cláusulas análogas. Por eso, en un supuesto así, lo procedente sería que la ley habilitase al juez para no aceptar el allanamiento y continuar con el proceso, hasta el dictado de la sentencia, en la que, en aplicación del art. 221.2 LECiv, podría manifestarse sobre la extensión de los efectos de la declaración de ilicitud a terceros, por ejemplo, a todas las empresas que empleasen cláusulas con un determinado contenido ${ }^{99}$.

Por último, cabe plantearse si es posible que las partes del proceso colectivo lleguen a un acuerdo o transacción como forma de poner fin a la controversia. Es decir, cabe cuestionarse si demandante y demandado podrían alcanzar un pacto que, al igual que la resolución judicial que pone

${ }^{98}$ Ver, por todas, la STS de 11 de noviembre de 1996.

${ }^{99}$ ARIZA (2012), p. 177. 
fin al proceso colectivo, fuese extensible a terceros o gozase de efectos erga omnes.

Como era de esperar, la regulación procesal española tampoco dice nada sobre la posibilidad de poner fin al proceso colectivo por medio de una transacción. Por su parte, el Código Modelo también es bastante parco en este aspecto, limitándose a señalar que, en la audiencia preliminar, el juez intentará la conciliación entre las partes y que, si esta se obtiene, el acuerdo al que lleguen será homologado por el juez constituyendo título ejecutivo (art. 11 párrs. $1^{\circ}$ y $4^{\circ}$ ).

Cabe preguntarse, en primer lugar, si esa conciliación tendría efectos ultra partes, igual que una sentencia alcanzada tras la celebración del proceso colectivo y del procedente juicio jurisdiccional. En este sentido, el Código Modelo sólo dispone que, obtenida la conciliación en la audiencia preliminar del proceso colectivo, se recogerá esta en sentencia, que constituirá título ejecutivo (art. $11^{\circ}$ párr. $4^{\circ}$ ), lo que interpretado conjuntamente con el art. 33, según el cual la sentencia estimatoria "hará cosa juzgada erga omnes", parece conducir a extender los efectos del acuerdo conciliatorio a terceros, no litigantes, pero pertenecientes al grupo o categoría en interés del que se litigó.

Así mismo, dispone el Código Modelo que, "preservada la indisponibilidad del bien jurídico colectivo, las partes podrán transigir sobre el modo de cumplimiento de la obligación" (art. 11 párr. $3^{\circ}$ ). En este sentido, hay que convenir con Gascón Inchausti ${ }^{100}$ en que la indisponibilidad sobre los derechos supraindividuales es relativa, en tanto que no implica, ineludiblemente, la imposibilidad de negociar acuerdos para transigir en relación con las formas en que se puede reparar el daño causado al bien supraindividual. Así pues, aun cuando el objeto mediato del proceso sea indisponible, las partes procesales podrían estar facultadas para disponer sobre el modo de solucionar la controversia o de reparar el daño causado por la conducta lesiva del demandado sobre ese bien supraindividual indisponible.

Por ejemplo, en un supuesto de daño ambiental, provocado por una empresa de hidrocarburos, evidentemente, no cabe que una asociación para la defensa del medio ambiente renuncie al derecho a un ambiente sano, en tanto que bien jurídico supraindividual perteneciente a un colectivo difuso y vinculado a valores superiores e irrenunciables, como podría ser la salud pública. Pero, sí que podría ser factible alcanzar un acuerdo sobre la forma en que se va a reparar el daño causado, ya través de la constitución de un fondo de compensación para los afectados, ya a través de la implementación

100 GASCÓN (2010), pp. 154 y 156. 
de un plan de recuperación del entorno dañado, ya a través de la realización de inversiones vinculadas a la prevención, etc.

En cualquier caso, es necesario advertir que, cuando se ejercita una acción de cesación o inhibitoria en relación con una actividad considerada ilícita, la tutela otorgada por este tipo de acciones, consistente en cesar en la conducta supuestamente ilícita viene, en gran medida, definida por la ley, con lo cual las posibilidades de transacción son mínimas, sin perjuicio de que se pueda transigir en relación con pretensiones acumuladas relativas a las formas de resarcimiento y/o reparación.

En España, al no prever nada la legislación procesal, no está claro que los sujetos legitimados para iniciar un proceso colectivo se encuentren, así mismo, legitimados para llegar a un acuerdo que sea oponible a terceros. Sobre todo si se repara en que la imperfecta regulación española establece una suerte de sistema opt-out, que no requiere que cada miembro del grupo manifieste su voluntad de adhesión para quedar vinculado al resultado del proceso, pero tampoco regula una forma concreta para ejercer el derecho de autoexclusión, más allá de permitir la personación individual de los interesados en el proceso, los cuales, cabe entender que podrían intervenir para manifestar su voluntad de autoexclusión o de litigar individualmente.

Relacionado con lo anterior, hay que considerar, por otra parte, que la transacción, como contrato que es, vincula sólo a las partes que lo suscriben, sin que nadie pueda contratar en nombre de otro sin su mandato o su autorización, salvo que, posteriormente, la persona a cuyo nombre se otorgó el contrato lo ratifique ${ }^{101}$.

Pues bien, partiendo de la naturaleza contractual de la transacción judicial ${ }^{102} y$, en aplicación de la regla general de relatividad o eficacia inter partes de los contratos (art. 1257 Código Civil español), parece que, en caso de que se llegara a una transacción en el marco de un proceso colectivo, incluso tras su homologación judicial, al menos en el caso de los intereses individuales homogéneos, su contenido sólo podría oponerse a aquellos terceros, titulares de los derechos en liza, que posteriormente ratificasen el acuerdo o se adhiriesen a él. No se encuentra fundamento, al menos con la regulación vigente en España, para sostener que aquellos miembros del

101 En este sentido, el art. 1259 del Código Civil español dispone que "ninguno puede contratar a nombre de otro sin estar por éste autorizado o sin que tenga por la ley su representación legal. El contrato celebrado a nombre de otro por quien no tenga su autorización o representación legal será nulo, a no ser que lo ratifique la persona a cuyo nombre se otorgue antes de ser revocado por la otra parte contratante".

102 TAmaYo (2002), pp. 565-570. 
grupo que no manifiesten su voluntad de autoexclusión del acuerdo quedarán sometidos al mismo ${ }^{103}$.

Esta necesidad de ratificación sería exigible en cuanto a los intereses pluriindividuales, en tanto que susceptibles de apropiación individual. Por el contrario, en lo que se refiere a los derechos supraindividuales, pertenecientes de forma indivisible a un colectivo, cabe entender que el legitimado para defenderlos en el proceso, también lo está para transigir en relación con los mismos, o más bien, como puntualiza el Código Modelo, en cuanto al modo de cumplimiento de la obligación. Este acuerdo tendrá, irremediablemente, efectos erga omnes, en tanto que la decisión que se adopte en relación con el bien supraindividual afectará, ineludiblemente, a todo el grupo o colectivo titular de aquel. Por eso, para su homologación judicial, además de tomarse en consideración los límites que se prevén para cualquier transacción, cuales son la ley, el interés general y los derechos de terceros, el juez deberá desplegar un riguroso control sobre el contenido del acuerdo, para asegurarse de que su efecto reparador satisface al colectivo o grupo de interesados.

Cabe señalar que, como regla general, en los procesos civiles en los que rige el principio dispositivo, el control judicial que se despliega para homologar una transacción suele ser, más bien, de carácter formal. En aplicación de la regulación española, el juez se limita a constatar la capacidad y el poder de disposición de las partes (art. 415.1 III LECiv), extremos que no suelen presentar dudas cuando los litigantes son titulares de los derechos en liza y tales derechos son esencialmente privados, pero que pueden ser problemáticos en un proceso colectivo. Además, el juzgador, al valorar el acuerdo, debe asegurarse de que no vulnera ninguna prohibición legal, que no contraviene el interés general y que no perjudica a terceros (art. 19.1 LECiv). Descartados estos incumplimientos, el juez procederá a homologar la transacción (art. 19.2 LECiv).

En las acciones colectivas, sin embargo, no es suficiente un control formal sobre los extremos indicados, sino que el juez debe examinar, de forma más activa, rigurosa y prudente, el contenido del acuerdo, de tal forma que se valore su potencial reparador para los bienes supraindividuales afectados y que se impida cualquier pacto que pueda menoscabar los derechos de los terceros titulares de los bienes en liza.

${ }_{103}$ Otra parece ser la solución del Código Modelo, al señalar que, obtenida la conciliación en la audiencia preliminar del proceso colectivo, se recogerá esta en sentencia, que constituirá título ejecutivo (art. $11^{\circ}$ párr. $4^{\circ}$ ), lo que interpretado conjuntamente con el art. 33, según el cual la sentencia estimatoria "hará cosa juzgada erga omnes", parece predicar un efecto ultra partes del contenido del acuerdo alcanzado en el proceso. 
Así pues, considerando el valor intrínseco que se vincula a algunos de los intereses en juego en los procesos colectivos e, incluso, en ocasiones, su cercanía a los intereses públicos o generales, es entendible que el juez ostente el poder-deber de controlar el concreto contenido de los acuerdos que puedan llegar a alcanzarse, así como su incidencia en la efectiva tutela de los bienes o derechos que pretenden protegerse jurisdiccionalmente a través del proceso colectivo.

Por otra parte, el juez no sólo debe de atender a la adecuación del acuerdo o a su razonabilidad, sino que tendrá que asegurarse, así mismo, de que respetan las garantías procesales, tanto de las partes formales como de los miembros ausentes del grupo o clase ${ }^{104}$. Así pues, según Armenta Deu "el control judicial y su intensidad es de hecho una de las cuestiones clave desde el punto de vista europeo, ya que se considera que entre las garantías jurisdiccionales figura velar por la justicia (fairness) de la resolución, centrada en buena medida en que no se vulneren los derechos de audiencia y de defensa"105. Evidentemente, al afectar el acuerdo a derechos de terceros, ajenos a la negociación y a la aprobación del mismo, el juez debe de estar especialmente atento para prevenir fraudes o abusos que se materialicen en la desprotección o el perjuicio de los derechos de tales terceros ausentes ${ }^{106}$.

Ambos controles, el relativo al contenido del acuerdo y el tendente a controlar que se han cumplido con las garantías de comunicación, notificación y posibilidad de audiencia a los interesados ya para desvincularse del acuerdo o para adherirse al mismo, ya para realizar aportaciones u objeciones, son necesarios en todos los procesos colectivos.

Ahora bien, en el caso de procesos sobre bienes jurídicos supraindividuales, las facultades judiciales de control se centrarán, sobre todo, en verificar que el contenido del acuerdo es apto para reparar el daño causado al bien jurídico lesionado. Por el contrario, en los procesos en los que se ventilan derechos pluriindividuales o individuales homogéneos, el control del juez ha de centrarse, sobre todo, en asegurar que se respetan las garantías de audiencia de los titulares individuales de los derechos en litigio, siempre que

\footnotetext{
104 En el control judicial de una transacción o un desistimiento, el juez federal norteamericano debe controlar que concurren los siguientes requisitos: fairness, reasonableness and adequacy (Rule 23 (e) (2) Federal Rules of Civil Procedure.

105 Armenta (2013 b), pp. 39-40.

106 Según GASCÓN (2010), p. 66, la experiencia norteamericana demuestra que para prevenir fraudes y abusos que perjudiquen a los miembros de la clase ausentes, el elemento determinante es el control judicial de la transacción, que ha ser real y efectivo, cerciorándose de que el contenido de lo pactado no lesiona injustamente derechos legítimos.
} 
estos resulten determinables. De hecho, en este último caso, el control sobre el contenido del acuerdo que debe realizar el juez debe complementarse, necesariamente, con el control difuso desplegado por los titulares de tales derechos individuales homogéneos, a los que habrá de darse una oportunidad real y efectiva de ser escuchados ${ }^{107}$.

La distinción entre las formas de control que deben desplegarse en los procesos colectivos, según los intereses en litigio sean supraindividuales o pluriindividuales, se justifica por el hecho, tantas veces referido, de que, en relación con los supraindividuales no cabe ejercicio de titularidad en sentido estricto o en el sentido tradicional del término, mientras que, tratándose de bienes pluriindividuales, la titularidad individual sobre los bienes resulta indiscutible, aun cuando se tutelen jurisdiccionalmente de forma colectiva o colectivizada.

Para el despliegue de los controles sobre el contenido de los acuerdos, tomando como referencia la perspectiva comparada, tanto Gascón Inchausti como Armenta Deu proponen acudir a dos concretos instrumentos. Por una parte, la designación de peritos de oficio y, por otra, la celebración de una audiencia para dar voz a los terceros interesados en el resultado del litigio ${ }^{108}$.

Así pues, en España, si se opta por permitir la transacción en procesos colectivos, existiría otro motivo para prever la posibilidad de designar peritos de oficio, a fin de que puedan auxiliar al juez en la comprensión y valoración del contenido de los acuerdos alcanzados por las partes del proceso, así como en la evaluación de su potencialidad reparadora, para todos o, al menos, para la mayor parte de los interesados. En este punto, como en tantos otros, el Código Modelo lleva ventaja, al prever, como regla general, la posibilidad de designar peritos de oficio.

Igualmente, sería conveniente regular la celebración de una audiencia, a la que serían citados los interesados en el resultado del proceso y en la que podrían realizar aportaciones u objeciones al contenido o a la aprobación del acuerdo $^{109}$. Aquí, nuevamente, habría que distinguir entre los procesos sobre

\footnotetext{
107 GASCÓn (2010), p. 195.

108 Gascón (2010), pp. 194-197; en la misma línea, ArmentA (2013 b), pp. 38-39, también apuesta por la audiencia a los interesados y el nombramiento de peritos.

109 Para la regulación de esta vista o audiencia se podría tomar como referencia la fairness hearing americana, que aparece prevista en la Rule 23 (e) (2). Así pues, en Estados Unidos, para la aprobación judicial de una transacción es necesario que el juez certifique que esta es justa, razonable y adecuada (fair, reasonable and adequate), para lo cual se celebrará una audiencia ante el tribunal, en la que la parte demandante tendrá que convencer al juez de que, efectivamente, el acuerdo cumple tales requisitos. La celebración de esta audiencia se comunica a todos los miembros de la clase para que puedan acudir a ella y, en su caso, formular objeciones, exigiéndose para ello que, previamente,
} 
derechos plurindividuales y supraindividuales, ya que, en los primeros sería necesario citar a esa audiencia a todos los titulares de los derechos discutidos y, en la medida de lo posible, acudir a formas de notificación personal, sin que, en otro caso, parezca justificado extenderles los efectos del acuerdo, salvo que voluntariamente se adhieran a él. Por el contrario, en el caso de bienes o intereses supraindividuales, la intervención en esa audiencia podría limitarse a determinados organismos o entidades representativos de los intereses en liza ${ }^{110}$.

El tema es tan interesante como complejo, por lo que no es posible analizarlo de modo exhaustivo en este trabajo. Basta con señalar aquí que la posibilidad de llegar a acuerdos en el proceso colectivo, con una regulación adecuada, que establezca claramente los poderes del juez para controlar el contenido del acuerdo y que permita a los terceros interesados, no personados en el proceso, adherirse y aprovecharse del mismo, podría presentar un enorme potencial, en tanto que forma ágil y eficaz de resolución de los conflictos de naturaleza colectiva.

\section{Conclusiones}

1. El proceso civil tradicional, pensado para resolver conflictos individuales, no sirve para tutelar de forma eficaz los intereses de grupo. El motivo radica en que las características del proceso colectivo chocan con lo más profundo del proceso civil, entendido como forma de resolución de un conflicto intersubjetivo, planteado por un sujeto que se presenta como titular del derecho en liza. De esto se deduce que los intereses supraindividuales o individuales homogéneos demandan una tutela específicamente colectiva, instrumentalizada a través de un proceso, el colectivo, regido por principios propios e integrado por instituciones propias.

2. Los principios procesales denominados estructurales o jurídico-naturales, básicamente, los de igualdad de armas, audiencia y contradicción, han de seguir rigiendo en los procesos colectivos, en tanto que son esenciales e

\footnotetext{
hayan anunciado por escrito su oposición, en un plazo preclusivo señalado al efecto. Sobre esta audiencia, véase GASCÓN (2010), pp. 57-61; también LóPEZ (2011), pp. 60 y 115.

110 En este sentido, sostiene GASCÓN (2010), pp. 163-164, al hilo de la posibilidad de transacción en los procesos colectivos que, en un proceso en el que se pretenda la tutela de bienes supraindividuales, si antes de aprobarse la transacción alcanzada entre demandante y demandando, se celebrase una audiencia, a ella deberían de poder asistir cualesquiera entidades legitimadas para el ejercicio de la acción, resultando dudosa la necesidad de permitir la participación en esta audiencia de consumidores a título individual, en tanto que no tendrían pretensiones propias que sostener y siempre podrían trasladar sus objeciones y/o alegaciones a través de alguna de las entidades legitimadas para ejercitar la acción.
} 
irrenunciables en cualquier proceso judicial. Por lo tanto, el proceso colectivo, sin perder de vista sus concretas funcionalidades y finalidades, debe de construirse normativamente, de tal modo que sea respetuoso con estos principios. En este caso, el proceso colectivo ha de adaptarse a tales máximas.

3. El principio dispositivo, al contrario que los principios procesales jurídico-naturales, no es trasversal y aplicable a cualquier proceso judicial, sino que se afirma en el proceso civil, en tanto que vinculado a los derechos materiales que subyacen, generalmente, en la relación procesal civil, de naturaleza privada y disponible. Por eso, dado que en los procesos colectivos, los derechos e intereses en liza ya no son estrictamente privados, ubicándose en la frontera entre lo público y lo privado, es necesario matizar o reinterpretar este principio, a la luz de las implicaciones y los efectos que despliega la tutela colectiva, incluso para terceros no litigantes. $Y$ otro tanto cabe afirmar en relación con el principio de aportación de parte. En este caso, es el principio el que debe adaptarse a la idiosincrasia de la tutela colectiva, y no a la inversa.

4. Las principales causas justificativas de las restricciones del principio dispositivo en las acciones colectivas se vinculan, por una parte, a la relevancia de los intereses en juego para la sociedad en su conjunto y, por otra, a los efectos que para terceros, no litigantes, puede tener el resultado del proceso colectivo. Así pues, parte de los poderes del juez se justifican por la necesidad de tutelar los derechos de los miembros del grupo o colectivo ausentes en el proceso.

5. Las matizaciones que está llamado a sufrir el principio dispositivo en los procesos colectivos se traducen en un incremento de los poderes del juez, tanto en sus posibilidades para dirigir formalmente el proceso de forma flexible, como en el incremento de sus facultades de dirección material del mismo. Esta transformación se manifiesta a lo largo de todo el iter procesal, afectando a la admisión de la demanda, a la elección de la tutela a otorgar, a la determinación del objeto procesal tanto desde el punto de vista objetivo como subjetivo, así como a la terminación anormal del proceso, ya por acuerdo o allanamiento del demandado, ya por desistimiento del actor.

6. Los acuerdos que las partes pueden alcanzar, como forma de poner fin al proceso colectivo, serán controlados por el juzgador, tanto en lo que se refiere a su contenido como a su forma de consecución. A tal fin, puede resultar necesario acudir a la designación de peritos de oficio, que ayuden al juez a valorar el potencial reparador del acuerdo, así como arbitrar mecanismos que permitan a los titulares de los bienes en liza, manifestar lo que tengan por conveniente en relación con la transacción a homologar. Tratándose de intereses individuales homogéneos será necesario que cada titular, no demandante, 
ratifique o se adhiera al acuerdo para poder oponérselo de forma legítima si pretendiere iniciar un proceso de reclamación individual.

7. El principio de aportación de parte que en los procesos civiles tradicionales viene a excluir o reducir a la mínima expresión la iniciativa probatoria del juez, en los procesos colectivos, más allá de cuestiones ideológicas, también demanda restricciones, que pasan por otorgar facultades al juzgador para acordar pruebas de oficio que complementen la actividad probatoria de las partes, así como para distribuir las cargas probatorias en función de la accesibilidad de las pruebas por las partes. Obviamente, el juez no podrá introducir hechos nuevos en la contienda procesal, pero debe poder acordar de oficio determinados medios de prueba para tomar una decisión lo más fundada posible, además de advertir a las partes sobre la insuficiencia de las pruebas por ellas propuestas.

8. La justificación de las limitaciones en la iniciativa probatoria de parte se encuentra en las mismas razones que conducen a una matización general del principio dispositivo en los procesos colectivos. Principalmente, en la relevancia social de los intereses en juego y en el hecho de que terceros, no partes, vayan a resultar, directa o indirectamente, afectados por el resultado del proceso. Ambas circunstancias desaconsejan que sea el demandante el que asuma en exclusiva todas las cargas procesales, en tanto que el éxito o fracaso de la pretensión desplegará efectos que trascienden su esfera jurídica individual.

9. La falta de regulación de un auténtico sistema de tutela colectiva en España resulta ciertamente preocupante. La introducción de preceptos aislados que, solo fragmentariamente, regulan aspectos concretos de las acciones colectivas, en una ley, como la LECiv, que responde a principios no solo distintos, sino en ocasiones antagónicos a los que debieran informar la tutela colectiva, crea asistematicidades y, sobre todo, dificulta la prestación de una efectiva tutela judicial de los derechos colectivos o de grupo.

10. De lege ferenda, se propone la regulación, en España, de un auténtico sistema de procesos colectivos, los cuales, en vista de su singularidad, deberían de figurar entre los procesos especiales del libro IV de la LECiv, en donde aparecen reglamentados los denominados procesos inquisitivos o necesarios, sobre capacidad, filiación, matrimonio y menores, que responden a principios opuestos a los del proceso civil tradicional, en ocasiones más acordes con los que han de informar la tutela colectiva. Pues bien, en el desempeño de esta ineludible tarea, el Código Modelo de procesos colectivos para Iberoamérica puede y debe servir de referente e inspiración al legislador español.

11. Entre tanto tal reforma legal no se produzca, la solución para tutelar de forma efectiva los derechos de grupo pasa por interpretar las disposiciones 
de la LECiv a la luz del art. 24.1 de la Constitución Española, según el cual "Todas las personas tienen derecho a obtener la tutela efectiva de los jueces y tribunales en el ejercicio de sus derechos e intereses legítimos (...)". Pues bien, a tal fin, será preciso que en los procesos colectivos el juez esté especialmente atento para prevenir fraudes, al igual que el Ministerio Fiscal, que debe personarse en todos los procesos de esta naturaleza. Además, sería conveniente que, en este tipo de procesos, se hiciera uso de aquellas posibilidades de advertencia a las partes que la LECiv recoge en materia de prueba y que, en la práctica, no suelen ser utilizadas por los tribunales en los proceso civiles de interés exclusivamente individual. Por último, también sería conveniente que, en general, las normas procedimentales se interpretasen de forma flexible y abierta, siempre con el límite del respeto al principio contradictorio y al principio de igualdad de armas.

\section{BibLIOGRAFíA}

AguirRezabal Grünstein, Maite (2010): "El control de la representatividad adecuada de las asociaciones de consumidores en el ejercicio de las acciones colectivas", en: Revista de Derecho (Vol. 23, № 2), pp. 175-196.

Ariza Colmenarejo, Ma Jesús (2012): La acción de cesación como medio para la protección de consumidores y usuarios (Navarra, Aranzadi).

Armenta Deu, Teresa (2013a): "Algunas reflexiones en torno a la convergencia entre los procesos civil y penal y la deriva común hacia métodos extrajurisdiccionales" en: A.A. V.V., Armenta, Teresa (coordinadora), La convergencia entre proceso civil y penal ¿Una dirección adecuada? (MadridBarcelona-Buenos Aires- Sao Paulo, Marcial Pons), pp. 227-254.

Armenta Deu, Teresa (2013b): Acciones colectivas: reconocimiento, cosa juzgada y ejecución (Madrid-Barcelona-Buenos Aires- Sao Paulo, Marcial Pons).

Barbosa Moreira, José Carlos (1984): "Tutela jurisdiccional dos interesses coletivos ou difusos", en: Temas de direito processual (terceira série) (Sao Paulo, Saraiva), pp. 196-197.

Bonet Navarro, José (2009): La prueba en el proceso civil (Barcelona, Tirant lo Blanch).

Bujosa VAdelL, Lorenzo (1995): La protección jurisdiccional de los intereses de grupo (Barcelona, Bosch).

Bujosa VADELL, Lorenzo (2007): "La protección jurisdiccional de los intereses de grupo (colectivos y difusos): Estado de la cuestión en España" en: Gimeno, Vicente (coordinador), El Tribunal Supremo, su doctrina legal y el recurso 
de casación. Estudios en Homenaje del profesor Almagro Nosete (Madrid, lustel), pp. 599-668.

Bujosa VAdelL, Lorenzo (2015): "La posición del juez en los procesos colectivos", en: Diario La Ley (15 de diciembre de 2015, No 6379), pp. 1-44.

CAPELETtI, Mauro (1975): "Appunti sulla tutela giurisdizionale di interessi coIlectivi o difusi", en: Giurisprudenza Italiana (IV, c. 55).

Carballo Piñeiro, Laura (2009): Las acciones colectivas y su eficacia extraterritorial. Problemas de recepción y trasplante de las class action en Europa (Santiago de Compostela, Universidad de Santiago de Compostela).

COUTURE, Eduardo Juan (1997): Fundamentos del derecho procesal civil, $3^{\text {a }}$ edición (Buenos Aires, Depalma).

De la Oliva Santos, Andrés; Aragoneses Martínez, Sara; Hinojosa Segovia, Rafael; Muerza Esparza, Julio y Tomé García, José Antonio (2007): Derecho procesal penal, 8 a edición (Madrid, Ramon Areces).

Díez-Picazo y Ponce de León, Luis; Gullón Ballesteros, Antonio (1988): Sistema de Derecho Civil (Madrid, Tecnos), Vol. I.

Gallego García, Elio (1996): Tradición jurídica y derecho subjetivo (Madrid, Dikynson).

Gascón InChausti, Fernando (2010): Tutela judicial de los consumidores y transacciones colectivas (Navarra, Civitas).

Gimeno Sendra, Vicente (1981): Fundamentos del Derecho Procesal (Madrid, Civitas).

Gimeno Sendra, Vicente (2010): Proceso Civil Práctico (Madrid, Editorial La Ley), Tomo I-1.

Goldschmidt, James (1936): Teoría General del Proceso (Barcelona, Labor).

Guasp Delgado, Jaime (1943): Juez y hechos en el proceso civil. Una crítica sobre el poder de disposición de las partes sobre el material de hecho del proceso (Barcelona, Bosch).

Lasarte Álvarez, Carlos (2007): Principios de Derecho Civil (Madrid-BarcelonaBuenos Aires, Marcial Pons), Vol. I.

López SÁnCHeZ, Javier (2011): El sistema de las class actions en los Estados Unidos de América (Granada, Comares).

Lozano-Higuero Pinto, Manuel (1983): La protección procesal de los intereses difusos: Intereses de los consumidores, ecológicos, urbanísticos, el acceso a la R.T.V. (Madrid, s.n.). 
Montero Aroca, Juan (2001): Los principios políticos de la nueva Ley de Enjuiciamiento Civil. Los poderes del juez y la oralidad (Tirant lo Blanch, Valencia).

Montero Aroca, Juan (2012): La prueba en el proceso civil (Navarra, Civitas). Montero Aroca, Juan (2017): "Los conceptos esenciales", en: A.A. V.V., Derecho jurisdiccional III. Proceso penal, 25 a edición (Valencia, Tirant lo Blanch), pp. 27-47.

Nieva Fenoll, Jordi (2001): La incoación de oficio de la instrucción penal (Barcelona, Bosch).

Nieva FenolL, Jordi (2012): Fundamentos de Derecho procesal penal (Buenos Aires, B de F).

Nieva Fenoll, Jordi (2014): Derecho procesal I. Introducción (Madrid, Marcial Pons).

Ovalle Favela, José (2013): "Legitimación en las acciones colectivas", en: Boletín Mexicano de Derecho Comparado (№ 138), pp. 1057-1092.

Palomo Vélez, Diego (2003): "Tutela del medio ambiente: abandono del paradigma de la Litis individual", en: Revista de Derecho (Vol. XIV), pp. 187-201.

Peyrano, Jorge (director) y LéPori White, Inés (coordinadora) (2008): Cargas Probatorias Dinámicas (Argentina, Rubinzal-Culzoni Editores).

Pellegrini Grinover, Ada (2002): "Ações coletivas iberoa-americanas: novas questões sobre a legitimação e a coisa julgada", en: Revista Iberoamericana de Derecho Procesal (año 2002, № 1), pp. 11-28.

Pellegrini Grinover, Ada (2014a): "A tutela jurisdiccional dos intereses difusos", en: A.A. V.V., Pellegrini, Ada; Herman, Antonio; Arruda, Teresa y Vigoriti, Vincenzo (coordinadores), Processo coletivo. Do surgimento à atualidade (Sao Paulo, Revista dos Tribunais), pp. 39-60.

Pellegrini Grinover, Ada (2014b): "Direito processual coletivo", en: A.A. V.V., Pellegrini, Ada; Herman, Antonio; Arruda, Teresa y Vigoriti, Vincenzo (coordinadores), Processo coletivo. Do surgimento à atualidade (Sao Paulo, Revista dos Tribunais), pp. 395-401.

Pérez-Cruz Martín, Agustín-Jesús (2015): Constitución y Poder Judicial, $2^{a}$ edición (Barcelona, Atelier).

Pérez-Cruz Martín, Agustín-Jesús y Seoane Spiegelberg, José Luis (2011): Derecho Procesal Civil, $2^{a}$ edición (Santiago de Compostela, Andavira), Tomo 1.

Tamayo Haya, Silvia (2002): El contrato de transacción (Navarra, Aranzadi).

TARUfFo, Michele (2005): "Modelos de tutela jurisdiccional de los intereses colectivos", en: Revista de Derecho Privado (No 9), pp. 23-33. 
TARUfFo, Michele (2006): "Poteri probatori delle parti e del giudice in Europa", en: Rivista trimestrale di diritto e procedura civile (Vol. 60, № 2), pp. 451-482.

VÁzquez Sotelo, José Luis (1995): "Discrecionalidad y Derecho Procesal", en: Justicia: Revista de Derecho Procesal (No 3-4), pp. 51-62.

VázQuez Sotelo, José Luis (2001): "Los principios del proceso civil", en: A.A. V.V., Caparrós, Eduardo (coordinador), Responsa lurisperitorum Digesta (Salamanca, Universidad de Salamanca), pp. 111-156.

VÁzquez Sotelo, José Luis (2007): "Los procesos colectivos", en: A.A. V.V., Gimeno, Vicente (coordinador), El Tribunal Supremo, su doctrina legal y el recurso de casación. Estudios en Homenaje del profesor Almagro Nosete (Madrid, lustel), pp. 901-938.

VÁzquez Sotelo, José Luis (2009): "Iniciativas probatorias del juez en el proceso civil", en: Justicia ( $\left.\mathrm{N}^{\mathrm{o}} 1-2\right)$, pp. 21-74.

Weinstein, Jack B. y Merger, Margaret. A. (1975): Weinstein's Evidence: Commentary on Rules of Evidence for the United States Courts and State Courts (California, M. Bender), Vol. III.

Zufelato, Camilo (2017): “La dimensión de la 'prohibición de la decisiónsorpresa' a partir del principio de contradicción en la experiencia brasileña y el nuevo Código Procesal Civil de 2015: reflexiones de cara al derecho peruano", en: Revista de la Facultad de Derecho PUCP ( $\left.\mathrm{N}^{\circ} 78\right)$, pp. 21-42.

\section{NORMAS JURÍDICAS CITADAS}

Real Decreto de 24 de julio de 1889 por el que se publica el Código Civil español (Boletín Oficial del Estado número 206, de 25 de julio de 1889) (España).

Federal Rules of Civil Procedure adoptadas el 16 de septiembre de 1938 (Estados Unidos).

Ley Orgánica No 5/1985, de 1 de julio, del Poder Judicial (Boletín Oficial del Estado número 157, de 2 de julio de 1985) (España).

Constitución Política de la República Federativa de Brasil adoptada el 5 de octubre de 1988 (Brasil).

Ley $N^{\circ} 83 / 95$, reguladora del derecho de participación procedimental y de acción popular (Diário da República, número 201, de 31 de agosto de 1995, pp. 5465-5467) (Portugal). 
Real Decreto № 1.828/1999, de 3 de diciembre de 1999, por el que se aprueba el Registro de Condiciones Generales de la Contratación (Boletín Oficial del Estado número 306, de 23 de Diciembre de 1999) (España).

Ley $N^{0} 1 / 2000$, de 7 de enero, de enjuiciamiento civil (Boletín Oficial del Estado número 7, de 8 de enero de 2000) (España).

Código Modelo de Procesos Colectivos para Iberoamérica aprobado en Caracas el 28 de octubre de 2004.

Real Decreto Legislativo 1/2007, de 16 de noviembre, por el que se aprueba el texto refundido de la Ley General para la Defensa de los Consumidores y Usuarios y otras leyes complementarias (Boletín Oficial del Estado número 287, de 30 de noviembre de 2007) (España).

Ley $\mathrm{N}^{\circ} 3 / 2014$, de 27 de marzo, por la que se modifica el texto refundido de la Ley General para la Defensa de los Consumidores y Usuarios y otras leyes complementarias, aprobado por el Real Decreto Legislativo $N^{\circ} 1 / 2007$, de 16 de noviembre (Boletín Oficial del Estado número 76, de 28 de marzo de 2014) (España).

\section{JURISPRUDENCIA CITADA}

STS de 11 de noviembre de 1996 (España).

STS 686/2003, de 30 de junio (España).

Tribunal de Justicia de la Unión Europea contenida en la sentencia de 14 de abril de 2016 (asuntos acumulados C-381/14 y C-385/14).

STS 123/2017, de 24 de febrero de 2017 (España). 
